'Ilu. Revista de Ciencias de las Religiones

ISSN: $1135-4712$

http://dx.doi.org/10.5209/ILUR.57416

\title{
Conciencia, cibercultura e interculturalidad
}

\author{
Salvador Pérez Álvarez ${ }^{1}$
}

Recibido: 6 de febrero de 2017 / Aceptado: 25 de marzo de 2017

Resumen. La promoción de la interculturalidad como modelo de gestión de la diversidad más respetuoso con el pleno disfrute de los derechos y libertades de todos los ciudadanos en condiciones de igualdad reales y efectivas, ha dejado de ser una utopía para convertirse en una realidad gracias a las interactuaciones socio-culturales que están teniendo lugar a través del Ciberespacio que constituye, junto a la educación, el nuevo paradigma de la interculturalidad en la Era Digital. Las relaciones sociales que tienen lugar en este contexto nacen de sentimientos o emociones tan intensos y enriquecedores como los que tiene lugar en la vida real, en la medida en que emergen de la esencia de la identidad personal, de la propia ideología o conciencia; y se rigen, en la mayoría de los casos, por el régimen de libertad que caracteriza a la cultura digital, para actuar conforme a las propias ideas, convicciones o creencias. Palabras clave: conciencia; diversidad; interculturalidad; ciberespacio; cibercultura.

\section{[en] Conscience, cyberculture and interculturality}

\begin{abstract}
Promotion of interculturality as a model of diversity management that is more respectful of the full enjoyment of the rights and freedoms of all citizens in real and effective equality conditions has ceased to be a utopia to become a reality, thanks to the social and-cultural relations that are taking place among equals belonging to different cultures through Cyberspace that constitutes, together with education, the new paradigm of interculturality in the Digital Age. Intercultural dialogues and exchanges taking place in this context are born of feelings and emotions as intense and enriching as those that take place in real life, insofar as they emerge from the essence of personal identity, of one's own ideology or conscience; And are governed, in most cases, by the regime of freedom that characterizes the digital culture, to act according to their own ideas, convictions or beliefs.
\end{abstract}

Keywords: conscience; diversity; interculturality; cyberspace; cyberculture.

Sumario. 1. Introducción. 2. El ciberespacio como nuevo paradigma de la interculturalidad. 2.1. Exclusión social, multiculturalismo e interculturalidad. 2.1.1. El modelo de exclusión social. 2.1.2. El modelo de asimilación. 2.1.3. Los modelos de integración. multiculturalismo e interculturalidad. a) El modelo multicultural. b) El modelo intercultural. c) Ciberespacio e interculturalidad. La cibercultura. 3. Conciencia, inteligencia intercultural y sabiduría digital. 3.1. Conciencia e inteligencia intercultural. 3.2. Conciencia y sabiduría digital. 4. A modo de conclusión. 5. Bibliografía.

Cómo citar: Pérez Álvarez, S. (2017), Conciencia, cibercultura e interculturalidad, en 'llu. Revista de Ciencias de las Religiones 22, 267-299.

1 Universidad Nacional de Educación a Distancia (España).

E-mail: sperez@der.uned.es 


\section{Introducción ${ }^{2}$}

Marx había advertido en 1859 que la cultura constituye una superestructura a la que se encuentra supeditado el Estado como comunidad política y el Derecho como conjunto de normas regladoras de esta realidad social ${ }^{3}$. Las tesis marxistas tuvieron un claro reflejo en los Textos constitucionales de principios del siglo XX que se consideran como esenciales en la conformación del Estado Social de Derecho, ya que contienen referencias expresas a la cultura como un fin propio del Estado ${ }^{4}$. La incorporación de la cultura como elemento arquitectónico del orden constitucional tiene sus raíces en lo que Ferguson denominará la sociedad civil ${ }^{5}$. El ilustrado escocés elabora su teoría sobre la base de que la sociabilidad forma parte de la esencia del hombre que actúa conforme a las leyes físicas innatas a su condición de ser humano, así como a las normas que nacen de los hábitos y/o costumbres que sirven para fortalecer, a su vez, su vida como miembro de la sociedad ${ }^{6}$. Los postulados del citado autor sirvieron de base para la formulación del concepto de sociedad civil por Habermas en su teoría de la acción comunicativa ${ }^{7}$. El sociólogo alemán considera que la sociedad es un conjunto activo de individuos, que se relacionan y colaboran entre sí para mantener y mejorar sus condiciones de vida. Así entendida, la sociedad se encuentra estructurada en dos dimensiones: por un lado, como ámbito de integración intersubjetiva o integración social; y, por otro lado, como acción coordinada que se encuentra dirigida a fines. La segunda de ellas la denomina Sistema (System), esto es, un conjunto funcional observable y describible mediante, el cual los miembros de una sociedad desarrollan su acción guiados por criterios racionales adecuados al control de sus circunstancias vitales que es lo que hace posible, a su vez, el desarrollo de la vida humana en sociedad y en su medio ambiente. Mientras que la integración intersubjetiva o social hace referencia al conjunto de estructuras comunicativas, lingüísticamente articuladas entre sí, mediante las cuales los individuos establecen el acuerdo básico que contienen las normas que rigen su cooperación en la acción del sistema. La integración social constituye, en cambio, el presupuesto básico de la acción comunicativa del hombre que es calificada por Habermas como el «mundo de la vida» (Lebenswelt). La sociedad, como mundo vital, es una red de cooperaciones entrelazadas a través de las tradiciones culturales comunes, que son las que aseguran la integración de los individuos en la sociedad ${ }^{8}$.

La cultura entendida como elemento de cohesión racional de la acción comunicativa de la sociedad civil, es la que da sentido a la propia existencia del Estado Social de Derecho también considerado como el Estado cultural ${ }^{9}$. Los hombres unidos por

2 Trabajo realizado en el marco del Proyecto de I+D dirigido por Ana Fernández-Coronado «Integra2. Claves jurídicas: derecho a la educación, diversidad religiosa y cohesión social». Referencia: DER2015-63640-P.

Marx, 1989, 8 ss.

4 Así, por ejemplo, el art. 18 de la Constitución de Weimar de 1919 se refiere al factor cultural como criterio para determinar las unidades políticas de la federación alemana; y el art. 11 de la Constitución española de 1931 considera a la cultura como un elemento importante para definir la estructura territorial del Estado. Vid. Ruiz Miguel, 2003, 211.

Marx, 1989, 7 .

Ferguson, 2010, 73 ss.

A quien se considera, por tanto, padre del concepto moderno de sociedad civil. Vid. Fascioli, 2009, 33 ss.

Habermas, 1999, 77 ss.

El Estado cultural es aquel que lleva a cabo una configuración activa de la cultura a través de la educación como ha acontecido en las Constituciones europeas de mediados-finales del siglo XX Así, por ejemplo, la cultura 
vínculos culturales de religión, de idioma, políticos o de cualquier otra índole ${ }^{10}$ son quienes han creado un aspecto físico unitario, una comunidad de sangre que se denomina raza secundaria o cultural ${ }^{11}$. La nación cultural es, pues, un producto de la historia de una determinada comunidad que se ha ido forjando en base a sus mitos y memorias, a sus valores y símbolos representativos de las señas de identidad de la colectividad que es la que dota de legitimidad política al propio Estado ${ }^{12}$. La comunidad se convierte en nación a través de la conciencia de la pertenencia a la colectividad $^{13}$, donde la cultura ya no es sólo el «mero adorno, confirmación y legitimación del orden social... actualmente es el medio común necesario, el fluido vital... la atmósfera común mínima y única en que los miembros de la sociedad pueden respirar, sobrevivir y producir» ${ }^{14}$. Al mismo tiempo, la incorporación de los derechos y libertades de los individuos como garantías institucionales del Estado ${ }^{15}$ es lo que ha hecho posible el surgimiento de sociedades abiertas, generadoras de nuevas formas de cultura diferentes a la históricamente predominante en la comunidad con la que se identifica el propio Estado ${ }^{16}$. Y es que la idea de cultura a la que nos referimos hace referencia a cualquier forma de identidad ${ }^{17} \mathrm{o}$ cosmovisión del mundo que es compartida por un número indeterminado de individuos ${ }^{18}$ y que constituye uno de los 5 Grandes atributos espirituales que conforman la esencia de la personalidad del ser humano ${ }^{19}$.

En este contexto político, el pluralismo aparece como el fundamento de la aceptación de la diversidad social en tanto que valor consagrado en el ordenamiento constitucional, como una realidad positiva. Como afirman Fernández-Coronado y Suarez Pertierra, «lo valioso socialmente hablando es esa diversidad plural que enriquece la convivencia, no la unidad $»^{20}$. En el siglo XXI, dos de las principales fuentes de creación de esta diversidad, entendido por tales los factores que son capaces de producir las trasformaciones culturales de una determinada sociedad; son los flujos

fue incorporada al orden constitucional a través de la educación en el Preámbulo de la Constitución francesa de 1946, en la Constitución italiana de 1947 (art. 33), en la Ley Fundamental de Bonn de 1949 (art. 5.3), en la Constitución griega de 1975 (art. 16.1 y 2), en la Constitución Portuguesa de 1976 (art. 23.2), en la Constitución española de 1978 (art. 27.2), en la Constitución holandesa de 1983 (art. 23.2) entre otras.

10 Abogamos en este trabajo por un concepto amplio de cultura que comprende las distintas costumbres, perspectivas o cosmovisiones del mundo que son expresión de la identidad personal que tienen en común los miembros del grupo o de la colectividad. Sobre los diferentes significados del término cultura vid. Kymlicka, 1996, 15 ss.

11 Heller, 1942, 174 ss.

12 Held, 2003, 37 ss.

13 Heller, 1942, 177 ss.

14 Cfr. Ruiz Miguel, 2003, 215.

15 Alexy, 1997, 23.

16 «Así, si por el principio de Estado social, el Estado asume la tarea de trasformar la sociedad o, al menos, de contribuir a su conformación de acuerdo a un modelo... esta estatalización de la sociedad se ve compensada por una cierta socialización del Estado». Cfr. Nuevo López, 2009, 14.

17 Llamazares Fernández, 2013, 66 ss.

18 Sartori, 2000, 62 ss.

19 En 1961 ambos investigadores estadounidenses publicaron un Informe elaborado por encargo de la División del ejército del Aire de las Fuerzas Armadas de los Estados Unidos de América en el que demostraron que la personalidad del ser humano está compuesta por cinco grandes factores o atributos espirituales que rigen el comportamiento humano ante diferentes tipos de situaciones o contextos: la extroversión, la amabilidad o cordialidad, la responsabilidad o conciencia, la estabilidad emocional y la cultura o apertura al cambio. Vid. Types - Christal, 1961, 6 ss.

20 Cfr. Fernández-Coronado - Suárez Pertierra, 2013, 23. 
migratorio ${ }^{21} \mathrm{y}$ las nuevas herramientas de comunicación que han nacido como consecuencia del desarrollo de Internet $2.0^{22}$.

La inmigración como fuente de la diversidad cultural genera una importante presión sobre la sociedad de acogida, más aún si tenemos en cuenta el corto espacio de tiempo en que se ha producido el auge del fenómeno al menos en Europa. Los sujetos de esta diversidad reivindican el reconocimiento de su cultura como un elemento que forma parte de su propia identidad y que no se puede desconocer ${ }^{23}$. Poco a poco, estas culturas se van incorporando a la propia comunidad en un constante procesos de asimilación y singularización con respecto a las culturas que originariamente conformaban este tipo de sociedades complejas ${ }^{24}$. La consolidación del fenómeno migratorio ha favorecido la consolidación de comunidades abiertas desde los puntos de vista cultural e interreligioso, en las que la defensa de los derechos de estas colectividades se convierte en una exigencia propia del Estado Social y de Derecho ${ }^{25}$.

Por su parte, Internet se ha convertido en uno de los principales medios de creación cultural en régimen de libertad de nuestros días ${ }^{26}$, como consecuencia del complejo entramado de relaciones sociales que están teniendo lugar en el Ciberespacio $^{27}$. El significado actual de este término ${ }^{28}$ fue acuñado por Barlow para referirse a un ámbito donde podrían tener lugar relaciones entre personas libres de ataduras físicas $^{29}$ : «Espacio social global... formado por transacciones, relaciones, y pensamiento en sí mismo, que se extiende como una quieta ola en la telaraña de nuestras comunicaciones. Nuestro mundo está a la vez en todas partes y en ninguna parte, pero no está donde viven los cuerpos $\rangle^{30}$. Las predicciones del citado autor se han hecho realidad a principios del siglo XXI, gracias al desarrollo de las herramientas de comunicación propias de la versión 2.0 de Internet $^{31}$ que lo ha convertido en un espacio abierto de comunicación creado artificialmente ${ }^{32}$, mediante la conexión mundial de equipos informáticos ${ }^{33}$, en el que está teniendo lugar el libre desarrollo de la personalidad y de la identidad personal de los individuos en sus relaciones con los demás ${ }^{34}$, de manera complementaria a las que se producen en los diferentes entornos analógicos o físicos donde tiene lugar su autodeterminación personal ${ }^{35}$. Este entorno

21 Como ya había puesto de manifiesto Kymlicka hace unas décadas «un país manifestará pluralismo cultural si acepta como inmigrantes a un gran número de individuos y familias de otras culturas y les permite mantener algunas de sus particularidades étnicas». Cfr. Kymlicka, 1996, 10.

22 Castells (II), 2003, 7 ss.

3 Fernández-Coronado - Suárez Pertierra, 2013, 28 ss.

Heller, 1942, 178 ss.

Contreras Mazarío, 2009, 175 ss.

Castells (II), 2003, 10.

Levine, 2004, 82 ss.

28 Los orígenes del término datan de la novela Neuromante del escritor Gibson donde ofrece la visión de un futuro invadido por microprocesadores, dispositivos electrónicos y quirúrgicos en el que la información es una mercancía de primera necesidad. Vid. Aparici, 2010, 9 ss.

29 Barlow acuñó el término Ciberespacio en su sentido actual en la nota de Presentación «Crime and Puzzlement» de su Electronic Frontier Foundation de 8 de junio de 1990. Vid. Barlow, 1990.

30 Barlow, 1996.

31 Internet 2.0 es una infraestructura artificial que se caracteriza, entre otras notas, por facilitar nuevos modos de organización colectiva a través de las tecnologías de la comunicación que permiten la interacción de unos individuos con otros a través de entornos digitales. Vid. Acedo Osuna, 2010, 136 ss.

32 «Ámbito creado artificialmente» como es definido en el Diccionario de la RAE.

33 Levy, 2007, 70 ss.

34 Beer, 2008, 526 ss.

35 Cotino Hueso, 2006, 27 s. 
permite que tengan lugar en tiempo real comunicaciones entre individuos pertenecientes a culturas diferentes, residan o no en el mismo territorio. Estas nuevas formas de socialización están contribuyendo a la creación de nuevas formas de culturalización en las sociedades contemporáneas ${ }^{36}$, pues, como ha afirmado Kozinets, nos hallamos ante un espacio que está siendo utilizado por los individuos para manifestar sus culturas, creencias, valores y costumbres que han sido trasmitidas de generación en generación, como pautas que presiden su comportamiento en sociedad ${ }^{37}$.

La convergencia de ambos factores ha dado lugar a una nueva concepción de la diversidad cultural que se caracteriza por su naturaleza multidimensionalı ${ }^{38}$. Nos hallamos ante un nuevo modelo de gestión de este pluralismo que ha nacido al amparo de la sociedad de la información y del conocimiento que no puede ser ignorada por los operadores públicos del Estado de Derecho, pues en una sociedad amparada en la vigencia de los valores democráticos, el respeto de las prácticas propias de las diversas culturas es algo obligado, porque estas prácticas inciden en los derechos fundamentales de las personas ${ }^{39}$. Pero ¿cuál es el impacto real del desarrollo de Internet a nivel global en relación con la gestión de la diversidad cultural de una sociedad dada? La búsqueda de una respuesta a esta cuestión constituye, en suma, el objeto de estudio del presente trabajo de investigación.

\section{El ciberespacio como nuevo paradigma de la interculturalidad}

\subsection{Exclusión social, multiculturalismo e interculturalidad}

La diversidad cultural de las sociedades contemporáneas viene siendo gestionada por los poderes públicos de un determinado país en base a tres modelos diferenciados entre sí: los modelos de exclusión social, de asimilación y de integración.

\subsubsection{El modelo de exclusión social}

El modelo de exclusión social se basa en la adopción de políticas y medidas legislativas de corte segregacionista, orientadas a desincentivar la llegada a un país determinado de nacionales de otros países que poseen señas de identidad cultural diferenciadas e, incluso, la puesta en marcha de acciones destinadas a relegar la participación social de los «otros» que ya se encuentran establecidos en la sociedad receptora ${ }^{40}$. La adopción de este tipo de políticas lleva consigo la exclusión cultural de estos individuos, entendida como «la marginalizacion de ciertos sectores sociales que no participan de los códigos básicos para comunicarse e interactuar con la comunidad (lenguaje, alfabetización, adherencia a valores), así como la discriminación en con-

36 Todo como consecuencia del carácter global y universal del Ciberespacio. Globalidad que como manifiesta Asis Roig «ha producido en el ámbito cultural dos grandes consecuencias: por un lado, lo que podríamos denominar como la "comunicación entre culturas", con lo que ello lleva de conocimiento de otras culturas o formas de entender el mundo y los seres humanos, de convivencia entre ellas y de tensión; y, por otro lado, lo que podrías denominar la "creación de las culturas", fruto precisamente de esas comunicaciones». Cfr. 2009, 49.

37 Kosinets, 2010, 12 ss.

38 Held, 2003, 49 ss.

39 Fernández-Coronado - Suárez Pertierra, 2013, 28 ss.

40 Lema Tomé, 2007, 28 ss. 
tra de ciertas personas consideradas de inferior categoría» ${ }^{41}$. Los poderes públicos de los Estados que adoptan este tipo de políticas acostumbran, como norma general, a controlar los flujos de información del Ciberespacio ${ }^{42}$ mediante programas que encriptan el contenido de la $\mathrm{Web}^{43}$ o impidiendo, incluso, que sus nacionales puedan entrar en relación social con personas de otras culturas ¡a través de entornos o comunidades virtuales, al denegarles el acceso a los mismos a través de los servidores locales de los que dependen la conexión a Internet en el territorio nacional ${ }^{44}$. La imposición de este tipo de límites da lugar a la denominada «exclusión digital» de los ciudadanos, que se traduce en situaciones más complejas de desintegración social como, por ejemplo, a procesos de marginación institucional, en donde las nuevas formas de ejercer la ciudadanía o el voto son potenciadas por el uso o no de las tecnologías, la imposibilidad de acceder a nuevas lógicas de consumo y comunicación propias de la sociedad de la información o, lo que es más grave aún, la pérdida de nichos de socialización en donde Internet ha adquirido un rol central en la definición de identidades ${ }^{45}$.

\subsubsection{El modelo de asimilación}

Por su parte, el modelo asimilacioncita tiene por objetivo principal garantizar la igualdad de oportunidades en y ante la ley entre los miembros de los colectivos que coextienden en una sociedad ${ }^{46}$. Ahora bien, la consecución de este objetivo se lleva a cabo mediante la adopción de políticas y propuestas «de uniformización cultural, se propone y se supone que los grupos y minorías van a ir adaptando la lengua, los valores, las normas, las señas de identidad de la cultura dominante y, en paralelo, van a ir abandonando su cultura propia» ${ }^{47}$. La finalidad de estas políticas no es tanto desincentivar la llegada de inmigrantes pertenecientes de otras culturas a la sociedad de acogida sino, más bien, de preservar la identidad cultural de la comunidad que es percibida por los ciudadanos como una cultura con «valor universal», frente a las demás culturas que son percibidas como una amenaza para la harmonía y la paz social ${ }^{48}$. Los sujetos pueden estar integrados económicamente y físicamente en la sociedad, manteniendo sus necesidades básicas cubiertas, mientras que culturalmente podrían estar inmersas en una situación de hecho de «exclusión social»" ${ }^{49}$, al estar condicionada su proceso de integración al abandono de las señas de identidad

41 Cfr. Raad, 2006, 2.

42 Watchbroit, 2004, 33 ss.

43 Levy, 2007, 178 ss.

44 Como ha puesto de manifiesto Castells: «En principio, el diseño de la red, a partir de una estructura en estratos layers, con capacidad distribuida de comunicación para cada nodo y transmisión por packet switching, operada por protocolos TCP/IP, según múltiples canales de comunicación alternativos, proporciona una gran libertad a los flujos de información que circulan por Internet... Sin embargo, si la Red es global, el acceso es local, a través de un servidor. Y es en este punto de contacto entre cada ordenador y la red global en donde se produce el control más directo. Se puede, y se hace en todos los países, negar acceso al servidor, cerrar el servidor o controlar quién comunica qué y a quién mediante una vigilancia electrónica de los mensajes que circulan por el servidor». Cfr. (II), 2003, 2s.

45 Raad, 2006, 2 ss.

46 Lema Tomé, 2007, 31 ss.

47 Cfr. Malgesino - Giménez Romero, 1997, 37.

48 Huntington, 2001, Cap. 3.

49 Raad, 2006, 2 ss. 
diferenciadas con respecto a la de la sociedad de acogida ${ }^{50}$, a la negación de sí mismos, de su cosmovisión del mundo y de la realidad y a su propia dignidad humana ${ }^{51}$. Al rechazar el proceso de asimilación, estos colectivos culturales se encuentran imprecisamente agregados en la sociedad receptora ${ }^{52}$, lo que genera, a la postre, sentimientos de rechazo a la cultura dominante y su segregación y discriminación social fuente, a su vez, de los conflictos interculturales que las políticas asimilacioncitas de gestión de la diversidad cultural pretendían evitar ${ }^{53}$.

Los poderes públicos de los Estados que abogan por la asimilación como modelo de gestión de la diversidad, aunque garantiza la igual libertad de acceso a Internet a todos los residentes en el territorio, tratan de preservar el relativismo cultural de la comunidad en este entorno de socialización ${ }^{54}$, ante la amenaza que supone para el mantenimiento del orden público y la paz social el intercambio cultural que puede tener lugar en régimen de libertad en el Ciberespacio ${ }^{55}$. Así sucede, por ejemplo, en el caso de Francia al que se alude en la Declaración de Independencia del Ciberespacio como uno de los países que están «intentando rechazar el virus de la libertad erigiendo puestos de guardia en las fronteras del Ciberespacio»: 1) Mediante programas que encriptan la información que circula en las redes locales a las que están conectados los soportes informativos de la región de que se trate ${ }^{56} ; 2$ ) A través de tecnologías o programas de vigilancia que permiten interceptar y controlar las relaciones sociales y los intercambios culturales que pueden tener lugar en los entornos digitales entre los ciudadanos que residen en el país y terceros pertenecientes a culturas diferenciadas ${ }^{57}$; ó 3) Mediante tecnologías que limitan las comunicaciones que puedan tener lugar a través de estos medios más allá de las fronteras físicas de su paí ${ }^{58}$. Nos hallamos, en suma, ante nuevas formas de «exclusión digital» debido a que el acceso equitativo a la Web, al estar encriptado y/o vigilada, no garantizaría necesariamente una mayor igualdad social desde el punto de vista cultural ${ }^{59}$, dado que los individuos pertenecientes a otras culturas, sólo obtienen información o pue-

50 Malgesino - Giménez, 1997, 37 ss.

51 Pues, como señala Olivé, los miembros de cada cultura pueden concebir la naturaleza de modos muy diversos, y lo que perciben como necesidades humanas básicas puede diferir del punto de vista de los demás. Los miembros de las diferentes culturas pueden tener maneras muy distintas de concebir el universo y la posición del hombre respecto al mismo, la relación entre el individuo y la sociedad, las obligaciones políticas de la persona con su comunidad o, inclusos, la propia concepción de dignidad humana como atributo espiritual consustancial a la condición de ser humano. Vid. 1999, 38 ss.

52 Kymlicka, 1996, 13.

53 Buena prueba de ello son los conflictos sociales acontecidos a principios del siglo XXI en diversas localidades, que fueron provocados por nacionales hijos de inmigrantes de tercera y/o cuarta generación en Francia que había adoptado políticas asimilacioncitas de integración social de los inmigrantes que se asentaban en el territorio nacional.

54 Lugo, 2016, epígrafe 2.2.

55 Levy, 2004, 171 ss.

56 Obligado a los usuarios a aceptar un filtro para acceder a Internet mediante un registro que tendrá los sesgos propios de la identidad cultural de la sociedad de acogida como realidad universal que debe ser asimilada por todos quienes deseen integrarse en la sociedad de acogida. Vid. Ugarte Fernández, 2010, 193 ss.

57 «Las tecnologías de vigilancia permiten interceptar mensajes, insertar marcadores gracias a los cuales se puede seguir la comunicación de un ordenador o un mensaje marcado a través de la red; también consisten en la escucha continua de la actividad de comunicación de un ordenador o de la información almacenada en dicho ordenador... Las tecnologías de vigilancia permiten identificar el servidor originario de un determinado mensaje. A partir de ahí, por colaboración o coacción, los mantenedores de los servidores pueden comunicar al detentor del poder la dirección electrónica de dónde provino cualquier mensaje». Cfr. Castells (II), 2003, 6.

58 Aparici, 2010, 16.

59 Raad, 2006, 4 ss. 
den socializarse y relacionarse en este entorno respetando las señas de identidad cultural propias de la sociedad de acogida, que es la imperante tanto en el mundo analógico como en el digital.

\subsubsection{Los modelos de integración. Multiculturalismo e interculturalidad}

En último término, el modelo de integración que puede ser definido, entre otras acepciones, como el proceso de incorporación de individuos pertenecientes a culturas diferenciadas a la sociedad receptora en igualdad de condiciones, derechos, obligaciones y oportunidades con los ciudadanos autóctonos preservando, a su vez, las señas de identidad cultural de los individuos ${ }^{60}$. La gestión de este modelo de integración social puede ser llevada a través de los paradigmas del multiculturalismo o/y la inter o transculturales.

\section{a) El modelo multicultural}

El multiculturalismo entendido ${ }^{61}$ como un modelo de gestión de esta diversidad ${ }^{62}$, se basa en la idea de organizar institucionalmente la diversidad de intereses e identificaciones culturales que convergen en la sociedad, de modo que sean respetadas por los demás miembros de la misma ${ }^{63}$, mediante la adopción de políticas que pueden ser de signo liberal o comunitarias.

En su concepción liberal, el Estado es neutral ante las diferencias culturales de los ciudadanos que, por tanto, no son tenidas en consideración como criterio para garantizar el pleno disfrute de sus derechos y libertades que tiene reconocidos en condiciones de igualdad formal con el resto de ciudadanos. Los signos de estas políticas no deben ni incentivar ni desinsectar la pertenencia o no de los individuos a los colectivos culturales en los que puedan agruparse ${ }^{64}$. Esto no significa, como afirma Marcos del Cano, que se pretenda una negación de las diferencias culturales, sino que las mismas no son relevantes para la vida pública, relegándolas a la vida privada. La prioridad aquí es el individuo y la libertad de los miembros del grupo ${ }^{65}$. La diversidad cultural se halla suficiente me amparada en la sociedad de que se trate, mediante el ejercicio de aquella libertad y de los mismos derechos civiles y políticos a todos los individuos, con independencia de su filiación o pertenencia a una cultura $u$ otra, sea la propia de la comunidad de acogida $u$ otra diferente ${ }^{66}$. Según Kymlicka:

60 Como ha puesto de manifiesto Lema Tomé «el término integración se caracteriza por una notable polisemia, especialmente en el campo de los estudios migratorios. Sus múltiples y muy diferentes acepciones hacen que este término en ocasiones sea equivoco y se utilice de forma arbitraria». Cfr. Lema Tomé, 2007, 28.

${ }_{61}$ El multiculturalismo es «un término que abarca todas las diferencias de perspectiva moral o identidad personal» de los diferentes colectivos que conviven en una comunidad plural». Cfr. Kymlicka, 1996, 16.

62 Así pues, debemos distinguir el concepto de multiculturalismo como «realidad social» que tiene una determinada presencia, intensidad y modos de expresión y el modo como se relacionan los protagonistas de esa realidad plural y el concepto de multiculturalismo como modelo de gestión de esa realidad. Vid. Giménez, 2003, 10 ss.

63 Rodríguez, García, 2007, 25.

${ }_{64}$ Ruiz Ruiz, 2005, 40 ss.

65 Marcos del Cano, 2009. 141 s.

66 Ruiz Ruiz, 2005, 44. 
«Estos derechos permiten a los individuos formar y mantener los diversos grupos y asociaciones que constituyen la sociedad civil, adaptar estos grupos a las circunstancias cambiantes $\mathrm{y}$, por último, fomentar sus perspectivas e intereses en la totalidad de la población... una de las funciones características de los derechos individuales es contribuir al mantenimiento de una amplia gama de relaciones sociales. De hecho, el derecho liberal más básico -la libertad de conciencia- es valioso fundamentalmente por la protección que otorga a las actividades intrínsecamente sociales (y no instrumentales) $)^{67}$.

Todo ello comporta que la supervivencia de una cultura concreta en la sociedad se encuentra supeditada a la acción comunicativa de los individuos y de las asociaciones en que se integren, de su capacidad para atraer a nuevos miembros y para trasmitir de generación a generación los valores, tradiciones y demás señas de identidad cultural de generación a generación ${ }^{68}$. Lo que, en devenir de los tiempos, ello puede dar lugar a conflictos internos entre los miembros de los grupos sobre qué valores o tradiciones son expresión de su identidad cultural ${ }^{69} \mathrm{o}$, incluso, a la desaparición de aquellas prácticas con las que tradicionalmente se identificaba la misma como estilo de vida, debido a que serían desplazadas por aquellas otras sentidas como más valiosas por los miembros del grupo.

Por su parte, en la concepción liberal del multiculturalismo, el reconocimiento, sin más, de los derechos a los miembros de estos colectivos en condiciones de igualdad formal con el resto de ciudadanos, no tiene como finalidad preservar la diversidad sino simplemente garantizar el ejercicio de los mismos sin medidas de signo prestacional que garanticen su derecho a la diferencia ${ }^{70}$. La ausencia de este tipo de políticas de promoción favorece, a la postre, que tengan lugar procesos de marginalización social de las culturas minoritarias que paulatinamente se pueden ir diluyendo entre la dominante que caracteriza a la sociedad receptora ${ }^{71}$. Pero es que, además, el multiculturalismo de signo liberal puede generar situaciones de discriminación múltiple de aquellos miembros que disiden de la concepción cultural imperante dentro del colectivo debido a que, a su vez, pueden ser objeto de discriminación cultural por parte de los demás ciudadanos bajo el falso imaginario de que sigue perteneciendo al grupo que también le está discriminando por su disidencia ${ }^{72}$. Para evitar este tipo de situaciones es necesario que el Estado intervenga adoptando medidas de protección de los derechos de los individuos a gozar de su propia cultura ${ }^{73}$, entendida siempre en sentido amplio, mediante políticas multiculturales de gestión de la diversidad de signo social que, a diferencia del de signo liberal, parte del presupuesto del reconocimiento de las identidades culturales diferenciadas como algo positivo para la comunidad ${ }^{74}$.

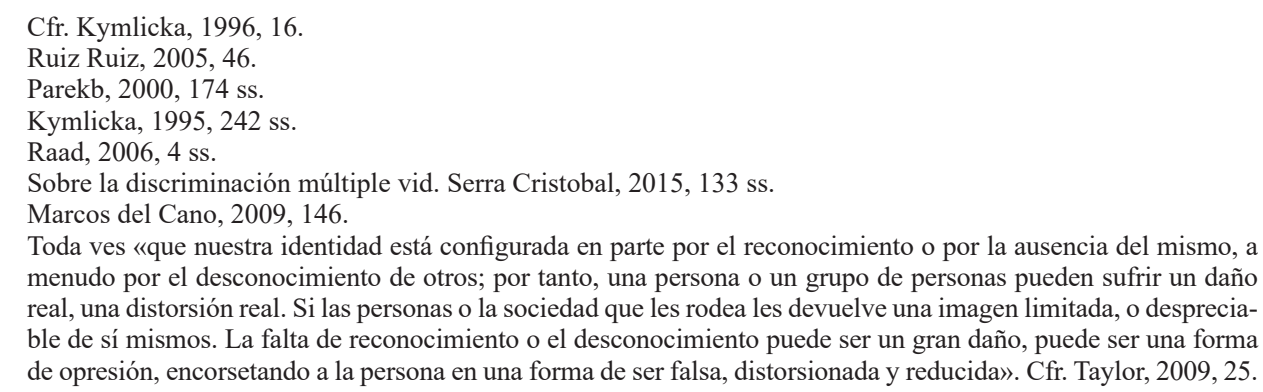
menudo por el desconocimiento de otros; por tanto, una persona o un grupo de personas pueden sufrir un daño real, una distorsión real. Si las personas o la sociedad que les rodea les devuelve una imagen limitada, o despreciable de sí mismos. La falta de reconocimiento o el desconocimiento puede ser un gran daño, puede ser una forma de opresión, encorsetando a la persona en una forma de ser falsa, distorsionada y reducida». Cfr. Taylor, $2009,25$. 
La identidad de una persona se define en relación a cómo los otros le identifican y cómo actúan esas otras personas en términos de grupos que siempre tienen asociados atributos, estereotipos y costumbres y tradiciones propias, en referencia a las cuales se conformaran la seña de identidad compartidas por todos sus miembros. A su vez, los diferentes grupos que conforman una comunidad plural, presentan diferentes necesidades, culturas, historias, experiencias y percepciones de las relaciones sociales que influyen en su concepción del mundo y en la interpretación del significado y consecuencias de las políticas de gestión de esta realidad, así como en su forma de razonar políticamente ${ }^{75}$. De ahí que los poderes públicos del Estado social de Derecho no deban ser indiferentes ante las demandas de estos colectivos, sino que deben adoptar todas aquellas medidas que garanticen la preservación de sus señas de identidad diferenciadas $^{76} \mathrm{e}$, incluso, todos aquellos programas y políticas de signo positiva o promocional de las mismas, cuando sea necesario, para que los miembros de esos colectivos sean realmente iguales al resto de ciudadanos en el ejercicio de sus derechos ${ }^{77}$.

La referencia a la existencia del pluralismo cultural supone admitir que existen diferentes formas de entender el mundo que, en la mayoría de los casos, tiene una dimensión normativa o conjunto de normas específicas de cada uno de ellos que son las que informan las relaciones sociales que mantienen sus miembros con los demás ${ }^{78}$. De ahí que, la intervención de los poderes públicos a través de acciones de discriminación positiva a favor de estos colectivos son del todo necesarias para que las diferentes culturas que convergen en una comunidad plural perdieren en el tiempo y, lo que es más importante, para sus integrantes no sean vean obligado a comportarse en sociedad conforme a tradiciones, costumbres o normas de socialización diferentes a las del grupo al que pertenecen que son expresión, a su vez, de sus señas de identidad cultural ${ }^{79}$. El problema reside en que esta concepción del multiculturalismo como modelo de gestión de la diversidad, aboga por la adopción de medidas garantistas o promocionales inclusivas de los colectivos culturales en la comunidad, bajo la consideración de que constituyen el medio o contexto social en el que sus integrantes pueden desarrollar con plenitud su personalidad ${ }^{80}$, pero al margen de sus derechos e intereses individuales que pueden ser o no convergentes con los del grupo en sí considerado, y más cuando la cultura es en sí una realidad dinámica que puede, por tanto, cambiar en el transcurso del devenir vital de las personas ${ }^{81}$. Cuando, en realidad, un Estado Social de Derecho es aquel que, por definición, reconoce derechos a los colectivos en que se integren los ciudadanos por razones de culturas, creencias, valores convicciones etc... siempre con carácter instrumental o subsidiario al hecho de que el individuo pueda desarrollar su personalidad en el grupo como contexto social más ${ }^{82}$, junto a los demás entornos sociales en que este proceso tiene lugar.

Y este es, precisamente, el principal inconveniente que presenta la concepción social del 1 de este modelo de gestión de la diversidad, dado que favorece la coexistencia de varias culturas en la comunidad, pero de manera aislada y separada unas de

\footnotetext{
Young, 1996, 107 ss.

Rodríguez García, 2007, 25 ss.

Taylor, 2009, 303 ss.

De Asis Roig, 2009, 49 ss.

Young, 1996, 108 ss.

Ruiz Ruiz, 2005, 57 ss.

Parekb, 2000, 234 ss.

Llamazares Fernández (I), 2011, 314 ss.
} 
otras, como consecuencia de que las políticas de integración multiculturalitas tratan de garantizar y, en su caso, promover los intereses y derechos colectivos frente a los propios de sus miembros. El sujeto que decida cambiar o abandonar la cultura de la que es originario como estilo de vida, puede quedar fuera del grupo y en situación de exclusión social ${ }^{83}$, al no pertenecer a ninguna de las expresiones culturales que conviven en la sociedad. Pues como afirma Llamazares Fernández:

«El aislamiento y la incomunicación, o una comunicación precaria, dificultan el mutuo conocimiento y favorecen que se vea al otro con recelo, más como potencial enemigo que como amigo, lo que llevará a los grupos a una afirmación cada vez más acusada de las diferencias como señales de la propia identidad, haciendo prácticamente imposible la capacidad para ponerse en el lugar del otro como premisa para la comunicación y el mutuo entendimiento. Algo que se recrudecerá si el otro es visto como un peligro del que hay que defenderse. Cuanto más tiempo se prolongue la lejanía, o en su caso los enfrentamientos, más se consolidarán las diferencias ${ }^{84}$.

Y en el devenir de los tiempos, estas diferencias son las que generan guetos, nuevos imaginarios de exclusión social y de discriminación de los miembros de estos grupos en la comunidad ${ }^{85}$ a causa de sus señas de identidad cultural diferenciadas que es lo que, precisamente, trata de paliar el multiculturalismo de signo social ${ }^{86}$.

Los contrastes existentes entre el multiculturalismo de signo liberal y comunitario o social, tienen una clara repercusión en las condiciones de acceso al ciberespacio como fuente de expresión y creación cultural por parte de los miembros de este tipo de colectivos. Ambos modelos parten de la premisa de que los poderes públicos que abogan por algunas de estas variantes de este modelo de gestión de la diversidad cultural se hacen eco de la Declaración de Independencia del Ciberespacio, al no imponer límites a al libre acceso al mismo, como espacio global de socialización. La diferencia entre una concepción u otra en esta materia estriba en si los poderes públicos ponen los medios necesarios que garanticen o no la libertad de acceso a internet a los miembros de estos colectivos, en condiciones de igualdad real y efectiva con el resto de ciudadanos, La principal traba a la que deben enfrentarse los miembros de estos grupos consiste en el coste de acceso a estos servicios, debido a que son prestados habitualmente por empresas del sector privado que imponen sus costes a los usuarios. Aunque actualmente las leyes de la competencia han abaratado los propios de los servicios básicos de acceso, los entornos virtuales 2.0 y sus actualizaciones más recientes requieren que el usuario disponga de un hardware con unos requerimientos técnicos específicos ${ }^{87}$ que, a su vez, no hacen más que encarecer el precio de mercado de acceso a los mismos. Actualmente, el acceso al Ciberespacio como entorno global de socialización y fuente de creación cultural implica, en suma, disponer de las interfaces de programas necesarios y de una velocidad de transmisión suficientes ${ }^{88}$ cuyos costes, sin embargo,

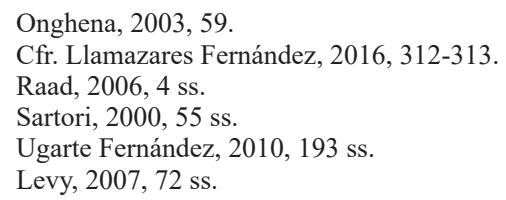


no pueden ser asumidos por todos los miembros de los colectivos culturales que convergen en la sociedad, y menos por aquellos que han nacido como consecuencia de los flujos migratorios, disponen de medios para sufragar este tipo de gastos secundarios ${ }^{89}$ frente a los de vivienda, manutención etc,, básicos o de subsistencia.

Las políticas multiculturales de signo liberal se limitan a reconocer el derecho de acceso a Internet a los ciudadanos, con absoluta independencia de su estatus económico o social y de sus señas de identidad cultural. La falta de recursos para que los individuos pertenecientes a aquellas culturas o colectivos más desfavorecidos que no puedan sufragar los costes de estos servicios, no puedan manifestar sus señas de identidad diferenciadas a través del Ciberespacio producen como resultado brechas digitales frente al resto de ciudadanos que, en realidad, son derivaciones de las situaciones analógicas de subdesarrollo y de exclusión socia $l^{90}$ a que dan lugar las políticas de integración social propias de este modelo de gestión de la diversidad. E, incluso, aunque tengan los recursos económicos necesarios para sufragar los costes de estos servicios, los miembros de las culturas procedentes de países en vía de desarrollo posiblemente carezcan de las competencias y destrezas digitales necesarias, para que puedan socializarse a través de los entornos virtuales $2.0^{91}$. En ambos casos, nos hallamos ante una nueva brecha de expectativas de estos individuos en el seno de la comunicada con respecto al acceso al Ciberespacio ${ }^{92}$, debido a que esta limitación lleva aparejada imaginarios y valoraciones que se han ido construyendo, dando paso a una nueva forma de exclusión cultural basada, principalmente, en el hecho de que la tecnología se ha constituido en una dimensión transversal y, por lo tanto, afecta actualmente a diferentes ámbitos de la vida cotidiana de nuestros días (tanto productivos como simbólicos) y al no cumplirse, las personas sienten o perciben que han quedado fuera de muchos otros procesos ${ }^{93}$.

En cambio, las políticas multiculturales de signo social garantizan y, en su caso, el derecho de acceso al Ciberespacio a todos los colectivos culturales que conforman la comunidad independientemente de su estatus económico o social para que puedan manifestar sus señas culturales de identidad mediante este tipo de medios para que no se produzcan brechas digitales con respecto al resto de ciudadanos. Siguiendo a Levy, la consecución de este objetivo podría llevarse a cabo mediante la adopción de alguna o algunas de las acciones siguientes:

- Implantación de puntos de acceso gratuitos al Ciberespacio en dependencias públicas.

- La subvención a las empresas prestadoras de Internet y de las interfaces necesarias a tasas reducidas adaptadas a los ingresos de la unidad familiar;

- La redistribución de equipos informáticos que van a ser desechados por las Administraciones públicas y que tiene los requisitos mínimos que garanticen una conexión optima a la Web.

\footnotetext{
89 Y más en la situación actual de crisis que ha llevado consigo el resquebrajamiento del Estado del Bienestar como garante de unas prestaciones sociales básicas y mínimas en muchos países que han pasado a convertirse en Estados económicos donde prima el poder del dinero y quienes lo poseen como gobernantes de la nación. Vid. Llamazares Fernández, 2016, 305 ss.

90 Galtson, 2004, 67 ss.

91 Prensky, 2004, 95 ss.

92 Levy, 2007, 106.

93 Raad, 2006, 4.
} 
- Impartición de cursos gratuitos sobre navegación por el Ciberespacio.

- Facilitar cuentas de correo electrónico gratuitas para los miembros de estos colectivos $^{94}$.

La instauración de estas medidas u otras similares evitarían que se produzca una brecha digital entre los miembros de los diferentes colectivos culturales que coexisten en la comunidad. Ahora bien, en base al modelo comunitario de multiculturalidad, estas medidas serían adoptadas por parte de las instancias públicas a favor del derecho de la diferencia y de promoción de la cultura a la colectividad y no de los individuos que los integran por lo que el colectivo, en aras a la defensa de su identidad común, podría supervisar las relaciones sociales de sus miembros mediante programas de vigilancia o de investigación de las comunicaciones instalados en los equipos informáticos que utilizan los miembros del grupo cuando se conectan al Ciberespacio. Todo ello con la finalidad de contralar si sus miembros interactúan en la Web al margen de las pautas o costumbre propias del grupo $\mathrm{o}^{95} \mathrm{o}$ si abandonan algunas de ellas o deciden cambiar de cultura como estilo de vida, como consecuencia de las relaciones sociales que pueda mantener en los entornos virtuales $2.0^{96}$. En tales circunstancias, el sujeto podría ser objeto de exclusión social dentro del colectivo cultural de origen, quedando marginado en la sociedad, salvo que sus relaciones sociales con personas pertenecientes a otras culturas se desarrollen en puntos de acceso instalados en instituciones públicas, que quedarían al margen de su ámbito de influencia, y que facilitarían el encuentro entre culturas a través del Ciberespacio, esto es, el dialogo intercultural.

\section{b) El modelo intercultural}

El interculturalismo es un modelo de integración social de la diversidad como una realidad positiva para la comunidad, cuya formulación más remita data de la Teoría del Cross-culturalism elaborada por Vogt en 1954 para referirse a las culturas resultantes de la mezcla entre sistemas autónomos de cultura (cultura en sentido amplio) que tuvieron lugar en los países europeos como consecuencia de los procesos de urbanización, industrialización y secularización con respecto a la religión ${ }^{97}$. Las teorías del antropólogo americano sirvieron para sentar las bases del interculturalismo en los debates sobre la instrucción pública en Francia, que nace vinculado a las acciones sociales que debían adoptarse para resolver los conflictos que planteaba la integración de los inmigrantes en el sistema educativo francés ${ }^{98}$. El Consejo de Europa se hizo eco de estas propuestas a principios de la década de los años 80 , que pronto se apresuró en concebir el modelo de interculturalidad como una de las claves para promover los derechos humanos, la democracia y el Estado de Derecho en las

\footnotetext{
Levy, 2002, 106 ss.

95 «Sí, en cambio, se puede proceder, desde cada centro de poder, a la identificación y subsiguiente represión de quienes sean los transgresores de las normas dictadas por dicho poder. Para ello, se dispone ahora de tecnologías de control que, en su mayor parte, fueron creadas por los empresarios informáticos que hacen negocio de cualquier cosa sin importarles demasiado los principios libertarios que afirman en su vida personal». Cfr. Castells, (I), 2013, 6 .

96 Parekb, 2000, 234 ss.

97 Barnett, 1954, ss.

98 Meunier, 2008, 1 ss.
} 
sociedades europeas contemporáneas. Y ya en 1993 se celebró la Primera Cumbre de Jefes de Estado y de Gobierno de los Estados miembros, donde se afirmó que la diversidad cultural caracterizaba el rico patrimonio europeo y que la tolerancia era la garantía de una sociedad plural y abierta ${ }^{99}$.

Los debates que desde entonces han tenido lugar en el Consejo han sido acogidos con vocación de validez universal en el concepto de interculturalidad elaborado por la $\mathrm{UNESCO}^{100}$ en 2005, que lo define como «la presencia e interacción equitativa de diversas culturas y la posibilidad de generar expresiones culturales compartidas, adquiridas por medio del diálogo y de una actitud de respeto mutuo» ${ }^{101}$. Así entendida, la interculturalidad se basa en el carácter dinámico de las culturas que, como afirma Abdallah-Pretceille:

«No se definen en relación a una suma de características y rasgos culturales sino a través de las relaciones y las interacciones entre los individuos y los grupos. Ya no es tiempo ni de nomenclaturas ni de mónadas sino de mezcolanzas, mestizajes, y transgresiones puesto que cada individuo tiene la posibilidad de expresarse y de actuar apoyándose no solo en sus códigos de pertenencia sino también en códigos de referencia libremente elegidos» ${ }^{102}$.

El modelo intercultural se fundamenta en el principio de respeto y de valoración de todas las culturas a un mismo nivel y con un mismo valor y la necesidad de interrelación entre ellas ${ }^{103}$ a través del diálogo intercultural concebido como intercambio de opiniones abierto y respetuoso, basado en el entendimiento mutuo, entre personas y grupos que tienen orígenes y un patrimonio étnico, cultural, religioso y lingüístico diferente dentro de las sociedades, entre las sociedades europeas, y entre Europa y el resto del mundo ${ }^{104}$. Así pues, las políticas de gestión de la diversidad basadas en este modelo, deben perseguir como finalidad primordial el fomento de las relaciones sociales entre los individuos y las culturas que conviven en la sociedad ${ }^{105}$, sobre la base del respeto mutuo, la vivencia del vínculo de la solidaridad y la aceptación de la diversidad como un valor positivo ${ }^{106}$. El éxito de las mismas conduce a una profunda trasformación de la comunidad que pasa a convertirse en una sociedad civil nueva en la que, como consecuencia de la interculturalidad, se relacionan en libertad culturas diversas, manteniendo y potenciando sus características propias pero que, a su vez, respetan y aceptan las diversas, mientras se crean y establecen nuevos lazos y pautas de convivencia en razón de los valores que todas ellas reconocen y asumen simultáneamente como propios y comunes ${ }^{107}$.

99 El éxito de esta Cumbre condujo a los Estados miembros a la elaboración del Convenio marco para la protección de las minorías nacionales (1995), al establecimiento de la Comisión Europea contra el Racismo y la Intolerancia (ECRI) y al lanzamiento de la Campaña europea de la juventud contra al racismo, el antisemitismo, la xenofobia y la intolerancia. Vid. Libro Blanco del Consejo de Europa sobre Dialogo Intercultural, 2008, 11,

100 Meunier, 2008, 3.

101 Art. 4.8 de la Convención sobre la protección y la promoción de la diversidad de las expresiones culturales, celebrada en París el 20 de octubre de 2005.

102 Cfr. Abdallah-Pretceille, 2006.

103 Vallespir, 1999, 48 ss.

104 Libro Blanco del Consejo de Europa sobre Dialogo Intercultural, 2008, 14,

105 Llamazares Fernández, 2016, 316.

106 Rodríguez García, 2007, 26 ss.

107 Calvo Espiga, 2003, 81 ss. 
Así pues, el paradigma de la interculturalidad se sitúa entre dos planos diferenciados, pero estrechamente relacionados en sí: el plano del saber o reconocimiento de lo diferente y el plano de la acción o el diálogo intercultural ${ }^{108}$. Ello implica, en primero orden de ideas, que las políticas de gestión de la diversidad basadas en este modelo, tendrán sentido y serán efectivas siempre y cuando las colectividades que conforman la diversidad tienen conciencia de cuál es su identidad cultural. Interculturalidad e identidad cultural se complementan entre sí, y deben ser contemplados de forma conjunta, en la medida en que el diseño de aquellas medidas requiere el reconocimiento positivo de cada cultura en sí considerada, pero en relación con las demás culturas que conviven en la comunidad ${ }^{109}$. A su vez, una vez asumida esta conciencia de grupo, los individuos que las integran deben adoptar una actitud de distanciamiento de los valores, tradiciones costumbres etc... que conforman dicha identidad $^{110}$, para poder así observar con objetividad y otorgar el mismo valor a las costumbres y tradiciones culturales ajenas, para poder apreciarlas como vivencias y experiencias cuyo reconocimiento puede contribuir muy positivamente al desarrollo de la personalidad en su dimensión individual, social y política ${ }^{111}$, de quien está observando al otro perteneciente a una cultura diferente ${ }^{112}$.

El éxito del proceso del reconocimiento sólo es posible si tiene lugar en claves de tolerancia entendida en sentido horizontal, es decir, como respeto (y sus consecuentes conductas jurídicamente obligadas) hacia la cultura del otro por más que sea distinta o, incluso, contraria a la propia, sin que esa diferencia influya en el respeto debido al disfrute de todos sus derechos y libertades en el seno de la comunidad, ni en el cambio, transformación o construcción de la propia identidad cultural. Este principio básico de convivencia en una sociedad plural implica, de un lado, el compromiso de respetar los derechos a la propia identidad y del derecho a la diferencia como base del pacto social por la convivencia en el seno de la comunidad ${ }^{113}$; y de otro lado, la búsqueda del consenso entre cuales son los valores comúnmente aceptados por todas las culturas como un mínimo común ético garantes de la paz social ${ }^{114}$. la igual dignidad de todos y el respeto a los derechos humanos que le son inherentes y los principios democráticos de pluralismo y laicidad como garantes de la neutralidad de la acción estatal ante la diversidad ${ }^{115}$. La adopción por parte de los poderes públicos de políticas que garanticen o, en su caso, promocionen la tolerancia entre culturas y el respeto a estos valores comunes, constituyen el presupuesto imprescindible para que del plano del reconocimiento se pueda pasar al plano de la acción ${ }^{116}$, esto es, para que pueda tener lugar el dialogo o las relaciones sociales interculturales entre iguales en una sociedad abierta y plural ${ }^{117}$.

Así concebido, el dialogo intercultural es:

\footnotetext{
8 Abdallah-Pretceille, 2001, 38 ss.

Vallespir, J. «Interculturalismo», ob. cit., pp. 55 ss.

Onghena, Y. «Reinterpretar para gestionar», ob. cit., p. 61.

Calvo Espiga, 2003, 81 ss.

Abdallah-Pretceille, 2005, 477 ss.

Llamazares Fernández, 2016, 291 ss.

Rodríguez García, 2007, 27 ss.

Leturia Navaroa, 2014, 559

Meunier, O. "Les approches interculturelles", ob. cit., pp. 4 ss.

Abdallah-Pretceille, 2001, 40 ss.
} 
«Un proceso que abarca el intercambio abierto y respetuoso de opiniones entre personas y grupos con diferentes tradiciones y orígenes étnicos, culturales, religiosos y lingüísticos, en un espíritu de entendimiento y respeto mutuos. La libertad y la capacidad para expresarse, pero también la voluntad y la facultad de escuchar las opiniones de los demás, son elementos indispensables. El diálogo intercultural contribuye a la integración política, social, cultural y económica, así como a la cohesión de sociedades culturalmente diversas. Fomenta la igualdad, la dignidad humana y el sentimiento de unos objetivos comunes. Tiene por objeto facilitar la comprensión de las diversas prácticas y visiones del mundo; reforzar la cooperación y la participación (o la libertad de tomar decisiones); permitir a las personas desarrollarse y transformarse, además de promover la tolerancia y el respeto por los demás» ${ }^{118}$.

Asimismo, este tipo de políticas deben garantizar y, en su caso, promover el conocimiento mutuo y el dialogo social haciendo especial hincapié en la importancia de la sociedad civil en la resolución de los conflictos culturales que puedan tener lugar en la comunidad día a día, colaborando con los poderes públicos en la resolución de aquellos que no podrán solucionar por sí solos ${ }^{119}$. A su vez, la participación activa y comprometida de todos los miembros de la comunidad en claves de interculturalidad, llevará consigo cambios en la identidad cultural de quienes participen en este proceso, que ya no se identificará única y exclusivamente con los rasgos propios de su cultura originaria, sino que podrán asumir, con una mentalidad más abierta, la propia diversidad y multiplicidad de la sociedad, en constante y rico dialogo con sus diferentes pertenencias y con las de $\operatorname{los} \operatorname{otros}^{120}$. En este sentido, la interculturalidad es importante para gestionar la pertenencia a múltiples culturas en una sociedad plural. Es un instrumento que permite hallar constantemente un nuevo equilibrio de la identidad, respondiendo a nuevas aperturas y experiencias, e incorporando nuevas dimensiones a la identidad personal de cada miembro de la comunidad, sin tener que renunciar necesariamente a las propias señas de identidad pero favoreciendo, frente al modelo del multiculturalismo, que cada persona tenga libertad para abandonar sus raíces culturales y comportarse libremente conforme a las tradiciones, y/o costumbres propias del resto de culturas que conviven en la sociedad ${ }^{121}$.

Ahora bien, la consecución de estos objetivos requerirá cambios por parte de los poderes públicos en la forma de gestión de la diversidad que deberán garantizar la adquisición de competencias y destrezas en materia de inteligencia intercultural mediante la educación ${ }^{122}$; $y$, hoy por hoy, en el contexto de la sociedad de la información y del conocimiento, deben fomentar el aprendizaje digital ${ }^{123}$, para que los miem-

118 Cfr. Libro Blanco del Consejo de Europa sobre Dialogo Intercultural, 2008, 21,

119 Leturia Navaroa, 2014, 559 ss.

120 Bermúdez Anderson, 2008, 79 ss.

121 Libro Blanco del Consejo de Europa sobre Dialogo Intercultural, 2008, 22 ss,

122 Abdallah-Pretceille, 2001, 43 ss.

123 Sólo mediante la adquisición de destrezas y competencias digitales todos los miembros de la comunidad podrán entrar en contacto con personas pertenecientes a otras culturas a través de su inclusión digital en el Ciberespacio. Como ha puesto de manifiesto Raad, el sentido objetivo de este nuevo medio de integración social estriba en que «cada persona conozca y maneje las herramientas o aplicaciones tecnológicas y accedan a estas, de manera que puedan aprovechar las oportunidades de consumo e intercambio de bienes (simbólicos o materiales) para lograr su integración... como un mecanismo real y practico del cual disponen para su desarrollo personal o social», Cfr. 2006, p. 4. 
bros de la comunidad puedan entrar en contacto con otros pertenecientes a otras culturas a través del Ciberespacio que constituye, en mi opinión, el paradigma presente y futuro de la interculturalidad en las sociedades occidentales contemporáneas ${ }^{124}$.

\section{c) Ciberespacio e interculturalidad. La cibercultura}

Ya en los años 60 del pasado siglo, los informáticos Engelbart y Licklider habían pensado en la posibilidad de crear una red de ordenadores conectados entre si al servicio de los procesos de comunicación colectiva ${ }^{125}$. Sólo han bastado 50 años para que sus creencias, la participación en suma de la sociedad civil en la protección y promoción del dialogo intercultural que propone la UNESCO ${ }^{126}$; hayan dejado de ser una utopía para convertís irse en una realidad, gracias a las relaciones sociales que están teniendo lugar entre iguales pertenecientes a culturas diferentes a través del Ciberespecio ${ }^{127}$. La consecución de este objetivo podría llevarse a cabo si los poderes públicos adoptasen alguna o algunas de las medidas a que nos referimos con anterioridad, cuando tratamos esta cuestión en relación con el modelo de multiculturalismo social, u otras similares que garanticen el acceso de todos los ciudadanos a los soportes e interfaces informáticos óptimos y necesarios para que puedan interactuar con los demás a través de comunidades $2.0^{128}$, en condiciones de igualdad real y efectivas. Siempre que, eso sí, estas comunicaciones fuesen verdaderamente libres y no estuvieran fiscalizadas mediante tecnologías de control o vigilancia por parte de las instancias públicas o de los colectivos culturales a los que pertenecen los ciudadanos; y de que, además, todos los miembros de la comunidad tengan los conocimientos necesarios para poder entablar relaciones sociales interculturales a través de este tipo de entornos. Sólo así se puede superar la brecha digital que se está produciendo actualmente entre unos ciudadanos y otros, más habida cuenta de los vertiginosos avances que este teniendo lugar en este campo de las telecomunicaciones en nuestros días.

El éxito de este tipo de políticas requiere que quienes carecen de estas habilidades reconozcan sus limitaciones intelectuales en esta materia y acepten recibir la formación que sea pertinente para poder navegar con solvencia por la $\mathrm{Web}^{129}$ que, además, debe ser facilitada por los poderes públicos, y en régimen de gratuidad a favor de quienes no tienen suficientes recursos económicos para sufragar los gastos derivados de la misma ${ }^{130}$. La alfabetización digital de todos los ciudadanos es uno de los retos de las sociedades contemporáneas ${ }^{131}$ para que tengan las mismas oportunidades

124 En la medida en que las relaciones sociales que están teniendo lugar en este tipo de entornos entre ciudadanos pertenecientes a culturas diferentes, el Ciberespacio se ha convertido en el paradigma por antonomasia del diálogo intercultural y en la construcción de nuevas identidades culturales en las sociedades democráticas contemporáneas. Sobre la influencia de la globalización de las comunicaciones como fuente de producción culturas vid. Held, 2003, 40 ss.

125 Levy, 2007, 98.

126 Art. 12 de la Convención sobre la protección y la promoción de la diversidad de las expresiones culturales, celebrada en París el 20 de octubre de 2005.

127 Peterson, 2004, 41 ss.

128 Levy, 2002, 106 ss.

129 Presnky, 2010, 94 ss.

130 Levy, 2002, 106.

131 La adopción por parte de los poderes públicos de políticas y programas que tienen por objeto la superación de las barreras a que da lugar la brecha digital entre los ciudadanos es una de las prioridades de la Unión Europea en su Programa Marco Horizonte 2020, con la finalidad de «fomentar una mejor comprensión de Europa, 
de interactuar en el Ciberespacio e intercambiar, entre otras acciones posibles, sus formas de expresión cultural que contribuyan a su desarrollo personal y comunitario con los demás ${ }^{132}$. Nuevas formas de socialización que se han intensificado actualmente a través de multitud de redes sociales y comunidades virtuales 2.0 a las que se accede mediante todo tipo de dispositivos y gracias, sobre todo, al uso a nivel global de smatphones que constituyen el paradigma por antonomasia de la dimensión socio-cultural del Ciberespacio ${ }^{133}$. Como ha constatado Castells:

«Internet, una vez que existe como tecnología potente insertada a la práctica social, tiene efectos muy importantes, por un lado, sobre la innovación -y, por tanto, la creación de riqueza y el nivel económico; y, por otro lado, sobre el desarrollo de nuevas formas culturales, tanto en el sentido amplio, es decir, formas de ser mentalmente de la sociedad, como en el sentido más estricto, creación cultural $\mathrm{y}$ artística» ${ }^{134}$.

Todo ello da lugar a una cultura digital que es comprensiva de los sistemas, prácticas, tradiciones y los medios culturales simbólicos propios de cada uno de los colectivos que conforman una sociedad plural (como los directamente relacionados con la información, la comunicación, el conocimiento o la educación) ${ }^{135}$. Todos ellos pueden ser transmitidas a través del Ciberespacio que se convierte en un entorno de socialización donde pueden participar activamente en la toma de decisiones que afectan a la vida política y civil de la sociedad, un entorno de encuentro de reconocimiento a sí mismos y de los demás, sus estilos de vida, reivindicaciones cívicas y políticas ya no sólo de quienes residen en el mismo Estado o localidad sino del mundo en general ${ }^{136}$, salvo con los nacionales de países como China, por citar

ofrecer soluciones y apoyar unas sociedades europeas inclusivas, innovadoras y reflexivas en un contexto de transformaciones sin precedentes y una creciente interdependencia mundial. Europa se enfrenta a enormes retos socioeconómicos que afectan de manera significativa a su futuro común, como la creciente interdependencia económica y cultural, el envejecimiento y el cambio demográfico, la exclusión social y la pobreza, la integración y la desintegración, las desigualdades y los flujos migratorios, el aumento de la brecha digital, la sensación decreciente de confianza en las instituciones democráticas y entre los ciudadanos dentro y fuera de las fronteras... Se trata de retos de gran envergadura que exigen un planteamiento europeo común, basado en el conocimiento científico compartido que pueden ofrecer, entre otras cosas, las ciencias sociales y las humanidades. Las desigualdades no solo sofocan el desarrollo de las sociedades, sino que perjudican a las economías de la Unión y reducen las capacidades de investigación e innovación dentro de cada país y entre países. Además, se espera que el número de europeos con edades superiores a los 65 años aumente de manera importante, en un 42\%, pasando de 87 millones en 2010 a 124 millones en 2030; las tasas de crecimiento económico y productividad de Europa llevan cuatro décadas disminuyendo en términos relativos. Estos retos han de abordarse conjuntamente y de forma innovadora y multidisciplinar, puesto que interaccionan de maneras complejas y con frecuencia imprevistas. La innovación puede debilitar la inclusión, como puede observarse, en fenómenos como la brecha digital o la segmentación del mercado laboral. A veces resulta difícil conciliar en las políticas la innovación social y la confianza social, por ejemplo, en las zonas socialmente deprimidas de las grandes ciudades de Europa. Fenómenos como el crecimiento de Internet, de los sistemas financieros, de la economía afectada por el envejecimiento y de la sociedad ecológica demuestran de forma evidente, que es necesario meditar sobre estas cuestiones y responder a ellas al mismo tiempo en sus dimensiones de inclusión e innovación».

Los objetivos específicos de los Retos de la Sociedad del Programa Marco Horizonte 2020 pueden ser consultados en el link: http://eshorizonte2020.cdti.es/index.asp?MP=87\&MS=715\&MN=1

132 Raad, 2006, 4-5.

133 Tascón - Quintana, 2013, 60 ss.

134 Cfr. (II), 2003, p. 8.

135 Levy, 2007, XVII.

136 Tascón - Quintana, 2013,61 ss. 
un ejemplo, han bloqueado las comunicaciones más allá de sus fronteras a través de los servidores locales de acceso a la Web ${ }^{137}$. Salvo en estos supuestos, se caracteriza por su carácter abierto, de libre acceso, para favorecer la libre comunicación global entre los ciudadanos ${ }^{138}$ que, desde el punto de vista de su dimensión cultural, está formado por transacciones, relaciones y pensamientos que se producen mediante un complejo entramado de comunicaciones que se reproducen a la vez en todas partes pero que, a su vez, no se encuentran localizadas en ningún espacio físico en particular ${ }^{139}$.

Las nuevas formas de socialización que están teniendo lugar en los entornos virtuales 2.0 no consisten solamente en informar o expresar una mera opinión o una simple idea sobre un determinado hecho o acontecimiento a los demás, sino que cada vez más frecuentemente son empleadas las mismas para manifestar emociones, sentimientos, convicciones y/o formas de expresión culturales que conforman la esencia de cada yo que se está comunicando con los demás internautas de la misma manera que lo hace en seno de su familia o grupo o colectivo al que pertenece ${ }^{140}$. El carácter on line del medio no resta intensidad ni humanidad a las emociones que experimenta la conciencia del sujeto al expresarlas ${ }^{141}$, sino que es exactamente la misma que sentiría si las manifestara a los demás cara a cara en todos los ámbitos analógicos donde se proyecta su vida social o comunitaria. Este tipo de relaciones sociales no sólo no sustituyen a las que tengan lugar en los entornos analógicos, sino que en la mayoría de los casos favorecen que este tipo de encuentros se produzcan cada vez con más frecuencia ${ }^{142}$, una vez superadas las barreras espacio temporales ${ }^{143}$. La autodeterminación personal en el Ciberespacio puede tener lugar individual o colectivamente, a través de los grupos que son creados en los propios entornos virtuales $2.0^{144}$ por quienes comparten las mismas áreas de interés, creencias, tradiciones costumbres en común etc... expresión de la dimensión comunitaria que también caracteriza a la cultura digital ${ }^{145} \mathrm{y}$ su régimen de funcionamiento interno se rige por las mismas o

137 Así lo ha manifestado Barlow en su Declaración de Independencia del Ciberespacio: «Nuestras identidades no tienen cuerpo, así que, a diferencia de vosotros, no podemos obtener orden por coacción física. Creemos que nuestra autoridad emanará de la moral, de un progresista interés propio, y del bien común. Nuestras identidades pueden distribuirse a través de muchas jurisdicciones. La única ley que todas nuestras culturas reconocerían es la Regla Dorada. Esperamos poder construir nuestras soluciones particulares sobre esa base. Pero no podemos aceptar las soluciones que estáis tratando de imponer... En China, Alemania, Francia, Rusia, Singapur, Italia y los Estados Unidos estáis intentando rechazar el virus de la libertad erigiendo puestos de guardia en las fronteras del Ciberespacio. Puede que impidan el contagio durante un pequeño tiempo, pero no funcionarán en un mundo que pronto será cubierto por los medios que transmiten bits».

138 Castells (I), 2003, 5 ss.

139 Barlow, 1996.

140 Aparici, 2010, 28.

141 Vélez Melo, 2012, 136 ss.

142 Y, de hecho, en la mayoría de los casos, las acciones de socialización que tiene lugar en la Web se encuentran sujetas a los mismos patrones y dinámicas de actividad que las acciones de socialización de los individuos en los diferentes ámbitos de la vida real donde tiene lugar su autodeterminación personal. Vid Tascón - Quintana, 2013,258 ss.

143 Levy, 2007, 100 ss.

144 «Este tipo de comunidades son colectividades personales, en cuanto que son agrupaciones humanas basadas en intereses, ideas y valores compartidas por las personas que las integran y, algunas de ellas, se rigen por pautas comunes de comportamiento, se encuentran dotadas de sus propios mecanismos de organización interna y ofrecen servicios de documentación, información y comunicación en función de las necesidades de los miembros que la integran». Cfr. Fernández-Coronado - Pérez Álvarez, 2013, 191.

145 Levy, 2007, 103 ss. 
similares normas estatuarias o reglas de conducta propias de las diferentes colectividades que conforman una sociedad plural ${ }^{146}$.

Ahora bien, relaciones sociales interculturales que se pueden entablar en Internet también entrañan una serie de riesgos que, en ocasiones, dificultan o impiden el desarrollo del modelo de interculturalidad. Así, por citar algunos ejemplos, los usuarios de la Web pueden ser víctimas de los actos xenófobos o de la incitación al odio racial por parte de usuarios de las Redes Sociales ${ }^{147}$; también pueden ser víctimas de ¡de actos encaminados a captar su atención para forzarles, posteriormente, a realizar en actividades en contra de su voluntad o, incluso, en casos más extremos, aprovecharse de la posible situación de exclusión social de un sujeto o un colectivo que ha migrado a otra sociedad culturalmente diversa, enajenar su conciencia en base a una malinterpretación intencionada del dogma de fe propia de las convicciones religiosas que las que se identifica su identidad cultural. Así está aconteciendo actualmente con al autodenominado Estado Islámico que se sirve de la Red como medio de captación de nuevos miembros de la citada organización en sociedades occidentes plurales ${ }^{148}$. La existencia de estos riesgos requiere la necesidad por parte de los poderes públicos y agencias implicadas a un continuo esfuerzo de actualización de sus conocimientos y premisas de actuación, así como imponer sanciones adecuadas hasta llegar al cierre inmediato de los dominios Web que fomenten este tipo de actividades ilícitas en el Ciberespacio y diseñar, en suma, una estrategia eficiente para neutralizar y prevenir este tipo de actividades que empanan las relaciones interculturales que están teniendo lugar actualmente en Internet.

En efecto, el progresivo aumento de este tipo de interacciones en Internet por parte de las nuevas generaciones ha favorecido la construcción de la Cibercultura como realidad social cada vez más rica y plural, en la que día a día participan un mayor número de ciudadanos, nativos o inmigrantes digitales. La gran mayoría de internautas no sólo expresas sus opiniones o juicios de valor sobre hechos concretos a través de los entornos virtuales, sino que cada vez son más participar activamente en este tipo de entornos, individual o colectivamente, para manifestar sus ideales, convicciones y/o formas de expresión cultural mediante aplicaciones que permiten socializarse en el mismo sentido con personas pertenecientes a culturas diversas ${ }^{149}$, independientemente del lugar o país de su residencia. Como ya había advertido Delgado Ruiz hace unas décadas, los encuentros interculturales que tiene lugar en la Web dan lugar a verdaderas nuevas formas de etnicidad, ya no basadas, como hasta entonces, en vínculos religiosos, idiomáticos, territoriales tradicionales, sino que se basan en parámetros estéticos y escenográficos compartidos en redes comunicacionales en común, por medio de un conjunto de estrategias de ritualización permanentemente activadas. Nos hallamos ante grupos humanos integrados, cuyo criterio de reconocimiento intersubjetivo se funda en un concierto entre conciencias de sus miembros ${ }^{150}$.

La anterior consideración nos permite afirmar que la participación en suma de la sociedad civil en la protección y promoción del dialogo intercultural que propone la

\footnotetext{
$146 \mathrm{Y}$, de hecho, «las multitudes conectadas llevan tiempo arrebatando a las elites narradoras (medios) los mecanismos (canales y códigos) para la construcción de la Realidad y han erosionado la legitimidad, con notable ayuda de los poderes políticos y económicos». Cfr. Tascón - Quintana, 2013, 253.

147 Pérez Luño, 2012, 124 ss.

148 Torres Soriano, 2009, 1 ss.

149 Levy, 2007, 215 ss

150 Delgado Ruiz, 1999, 118.
} 
$\mathrm{UNESCO}^{151}$; haya dejado de ser una utopía para convertirse en una realidad, gracias a las interactuaciones socio-culturales que están teniendo lugar entre iguales pertenecientes a culturas diferentes a través del Ciberespacio que hoy por hoy constituye, junto a la educación ${ }^{152}$, el paradigma de la interculturalidad en la Era Digital. Los diálogos e intercambios interculturales que tienen lugar en este contexto nacen de sentimientos o emociones tan intensos y enriquecedores como los que tiene lugar en la vida real, en la medida en que emergen de la esencia de la identidad personal, de la propia ideología o conciencia; y se rigen, en la mayoría de los casos, por el régimen de libertad que caracteriza a la cultura digital ${ }^{153}$, para actuar conforme a las propias ideas, convicciones o creencias, esto es, la propia ideología o conciencia de los internautas ${ }^{154}$.

\section{Conciencia, inteligencia intercultural y sabiduría digital}

Según el Diccionario de la RAE, el término ideología hace referencia al «conjunto de ideas fundamentales que caracteriza el pensamiento de una persona, colectividad o época, de un movimiento cultural, religioso o político, etc...». Ahora bien, la ideología subyacente a cualquier cultura no comprende única y exclusivamente los actos del entendimiento o pensamiento humano ${ }^{155}$, sino también aquellas ideas en que se fundamenta el raciocinio humano ${ }^{156}$ y que, como advierte Ortega y Gasset, «constituyen el continente de nuestra vida y, por ello, no tienen el carácter de contenidos particulares dentro de ésta» ${ }^{157}$. El conjunto de ideas que forman parte de la esencia de la realidad personal de cada sujeto, son definidas por el citado autor como creencias ${ }^{158}$ que, a diferencian de las simples ideas, opiniones o pensamientos, son consustanciales a la propia identidad personal del ser humano ${ }^{159}$. Las ideas fundamentales o creencias constitutivas de una ideología se confunden con la realidad misma ${ }^{160} \mathrm{y}$ las percibimos como propiedades inseparables de nuestra identidad a través de su conciencia, esto es, «la propiedad del espíritu humano de recocerse en sus atributos esenciales y en todas las modificaciones que en sí mismo experimenta» como un individuo yo distinto a los demás ${ }^{161}$. La ideología es lo mismo que la conciencia, pero definida por su objeto formal. Si hablamos desde la perspectiva de la capacidad

151 Art. 12 de la Convención sobre la protección y la promoción de la diversidad de las expresiones culturales, celebrada en París el 20 de octubre de 2005.

152 Abdallah-Pretceille, 2001, 44 ss.

153 Pues como ha manifestado Castells «Internet, en nuestro tiempo, necesita libertad para desplegar su extraordinario potencial de comunicación y de creatividad. Y la libertad de expresión y de comunicación ha encontrado en Internet su soporte material adecuado. Pero tanto Internet, como la libertad, sólo pueden vivir en las mentes y en los corazones de una sociedad libre, libre para todos, que modele sus instituciones políticas a imagen y semejanza de su práctica de libertad». Cfr. Castells (I), 2003, p. 16.

154 Llamazares Fernández (I), 2011, 17 ss.

155 Este es el significado actual del término «ideas» frente a su sentido originario o «visión» que procedía de la traducción literal del término griego «eidos». Vid. Tarodo Soria, 2004, 65 ss.

156 Esta es la primera acepción que atribuye el Diccionario de la Real Academia Española a la palabra «fundamento» que procede del término latín «fundamentum».

157 Cfr. 1995, 24.

158 Ortega y Gasset, 1995, 24.

159 (I), 2011, 17 ss.

160 Ortega y Gasset, 1995, 24.

161 Llamazares Fernández (I), 18 ss. 
para la auto percepción como sujeto diferenciado y libre, hablamos de conciencia, mientras que si queremos referimos fundamentalmente al sistema de convicciones en las que se concreta como resultado esa percepción, hablamos de ideología. Así entendida, la conciencia es uno de los cinco grandes factores o atributos esenciales de la personalidad del ser humano que se encuentra íntimamente relacionada con el de la cultura, según el modelo teórico de Types y Christa ${ }^{162}$.

En efecto, las ideas fundamentales consustanciales a la ideología o conciencia personal son las mismas sobre las mismas sobre las que hunde sus raíces la idea de cultura que hemos adoptado como punto de partida en este trabajo como expresión de cada una de los estilos de vida que coexisten en las sociedades plurales contemporáneas. En otras palabras, la identidad personal que constituye la piedra angular de la conciencia está conformada por aquellas creencias o convicciones que determina la manera de actuar y de relacionarse con los demás de cada individuo y que son producto de las características propias de la cultura a la que pertenece cada persona. A su vez, como hemos visto con anterioridad, la cultura se caracteriza, entre otras notas, por su carácter dinámico, por lo que las señas de identidad culturales de cada sujeto pueden cambiar o asumir nuevos valores o creencias cuando entra en contacto otras culturas, ya sea de manera individual o colectiva ${ }^{163}$. La incorporación de estos atributos nuevos a la esencia de la personalidad tiene lugar mediante un conjunto de actos cognitivos que afectan a su ideología o conciencia ${ }^{164}$ que, al cambiar, se convierte en la fuente subjetiva de la construcción de la nueva forma de expresión cultural ${ }^{165}$ que nace del diálogo intercultural entre los individuos y/o los colectivos culturales ${ }^{166}$, tanto en el mundo real como en el Ciberespacio. El éxito o no de este tipo de forma de socialización interculturales y, en general, en las políticas de interculturalidad como modelo de gestión de la diversidad va a depender, eso sí, del nivel de inteligencia intercultural y, en el caso de las relaciones sociales que se produzcan en comunidades virtuales 2.0 , de la alfabetización digital de cada miembro de la comunidad.

\subsection{Conciencia e inteligencia intercultural}

En las sociedades plurales contemporáneas, ya desde el nacimiento el individuo vive en un entorno heterogéneo y pluricultural, no puede ignorar la existencia de otras identidades culturales, tanto individuales como colectivas, de otras formas o estilos de vida, vive, forma y comienza a comportarse en base a su propia ideología o con-

162 Types - Christal, 1961, 6 ss.

163 Lema Tomé, 2007, 146 ss.

164 Abdallah-Pretceille, 2001, 40 ss.

165 En este sentido, coincidimos con Llamazares Fernández cuando afirma que «la conciencia es al mismo tiempo creadora y receptora de cultura, ya que parte integrante de ella, las más importante, son las creencias e ideas (convicciones) con las que vamos urdiendo nuestra propia historia». Cfr. (II), 2011, 18.

166 Bajo la perspectiva de la conciencia individual, las vivencias que experimenta un sujeto al percibirse a sí mismo como un sujeto valioso y al reconocer que quienes pertenecen a otras culturas diversas son otros igualmente valiosos son la causa de la necesidad inexorable de entrar en dialogo con los demás. Vid. Llamazares Fernández, 2005,398 ss.

Todo ello se debe a que la ideología o conciencia personal sobre la que hunde sus raíces cada forma de expresión cultural también se caracteriza por su naturaleza o dimensión social que, como fundamento último de la personalidad individual, ha de expresarse y manifestarse en la actuación y proyección social del hombre en su relación consigo mismo y con «los otros». Vid. Calvo Espiga, 2003, 81 ss. 
ciencia en un contexto de socialización plural, disponiendo de una amplia gama de culturas o estilos de vida a elegir muy diferentes entre sí y diversos a las raíces culturales de su familia ${ }^{167}$. Uno de los factores psicológicos que poseen una influencia decisiva en su libre desarrollo de la identidad personal es la autopercepción del yo como sujeto individual y el reconocimiento de que los demás como otro yo diferente a mi ser pero que, al mismo tiempo, posee la misma conciencia y, a priori, las mismas capacidades intelectuales para tomar decisiones en base a los imperativos de la misma y de las habilidades emocionales para relacionarse con los demás. El reconocimiento y aceptación en los demás de esta misma realidad genera en la necesidad emocional intrínseca del sujeto de entrar en dialogo con ellos, pertenezcan o no a la misma cultura, así como la necesidad emocional de ordenar la vida en común entre identidades culturales diversas, tanto individuales como colectivas, en base a políticas sociales de consenso ${ }^{168}$. Dese esta perspectiva, las diferencias culturales entre los individuos y/o colectivos no se definen como daos objetivos de carácter estadístico, sino como reacciones dinámicas entre dos o más entidades que se dan sentido a sí mismas ${ }^{169}$.

La ordenación de la vida en común exige, entonces, una alfabetización funcional de la población de las sociedades plurales ${ }^{170}$, que desemboque en un acuerdo de mínimos (pacto por la convivencia) sobre las normas de conducta de los ciudadanos de identidad cultural diferente, de unos con respecto a otros y de los poderes públicos con respecto a todos ellos, para garantizar una convivencia no sólo pacífica, sino también fecunda y enriquecedora ${ }^{171}$. A este respecto, Schwartz considera que para poder adaptarse a esta realidad sociocultural, los individuos y los colectivos culturales en que se integran transforman las necesidades propias de la existencia humana expresándolas en el lenguaje de los valores específicos mediante los que pueden comunicarse $^{172}$. La responsabilidad y las consecuencias derivadas de las relaciones con los demás ya no es sólo una cuestión del ordenamiento constitucional democrático como garante de la paz social en este tipo de sociedades plurales; sino que pasa a convertirse en una cuestión de ética personal, de la conciencia individual, que no puede ni debe desarrollarse a partir de la reflexión sobre uno mismo sino sobre el

167 Abdallah-Pretceille, 2001, 39 ss.

168 Llamazares Fernández, 2005, 400 ss.

169 Abdallah-Pretceille, 2001, 41 ss.

170 Desde la década de los años 70 la UNESCO ha hecho especial hincapié en la necesidad de que los poderes públicos de los Estados democráticos lleven a cabo políticas educativas cuyo objeto primordial se la alfabetización funcional de la población concibiéndola «como un componente de los proyectos de desarrollo económico y social. La alfabetización funcional se distingue de la tradicional en que no se trata de una acción aislada, distinta, ni siquiera de un fin en sí, sino que permite considerar al analfabeto como individuo o como miembro de un grupo, en función de un medio dado y de una perspectiva de desarrollo. Por principio, un programa de alfabetización funcional guarda relación con necesidades colectivas e individuales precisas; está concebido "a medida", diferenciado según los medios y teniendo en cuenta objetivos económicos y sociales determinados. EI objetivo que los partidarios de la alfabetización tradicional tratan de lograr, con sus programas, es un dominio suficiente de los mecanismos de la lectura, de la escritura y del cálculo elemental; no persiguen otro fin que proporcionar a los analfabetos un medio que les dé acceso a la comunicación escrita o impresa. En cambio, dentro de un programa de alfabetización funcional, el aprendizaje de la escritura y la lectura y la formación profesional no pueden desarrollarse paralelamente ni ser disociados cronológicamente: son actividades integradas. La alfabetización tradicional se caracteriza por un enfoque extensivo y difuso. En cambio, en la alfabetización funcional el enfoque es global, en relación directa con la adquisición de aptitudes profesionales y de conocimientos utilizables en un medio determinado». Cfr. Informe de la UNESCO, 1970, 9.

171 Llamazares Fernández, 2016, 66 ss.

172 Schwartz, 1994,19 ss. 
otro y su total y absoluta libertad y responsabilidad ${ }^{173}$. A su vez, el éxito o no de este tipo de encuentros se encuentra supeditada a la inteligencia intercultural de cada sujeto, esto es, la capacidad individual para entenderse eficazmente con personas de culturas diferentes ${ }^{174}$, para suspender o cambiar algunas modalidades culturales adquiridas y para aprender y acomodar algunas de las nuevas modalidades culturales, encontrando creativamente maneras de gestionar las dinámicas relativas a los papeles inter-grupos diferentes ${ }^{175}$.

La inteligencia cultural es una de las inteligencias múltiples que conforman el raciocinio de quienes residen en sociedades plurales según las tesis de Gardner ${ }^{176}$ que se va desarrollando a lo largo del devenir vital como uno de los atributos cognitivos de la personalidad ${ }^{177}$ a través la propia conciencia ${ }^{178}$. La adquisición de las competencias $^{179}$ necesarias para que el individuo la desarrolle de forma dinámica, requiere un constante aprendizaje de interacciones sociales, en los cuales se prioriza la focalización atencional y apreciación crítica sobre diferencias culturales observables en uno mismo y en personas pertenecientes a otras culturas. Las habilidades perceptuales incluyen la apertura consciente y deliberada hacia la observación reflexiva de conductas culturales, niveles óptimos de tolerancia a la incertidumbre y suspensión de prejuicios. Las habilidades relacionales necesarias para aprender nuevas experiencias en contextos foráneos incluyen flexibilidad, sociabilidad y empatía. Las habilidades adaptativas singularizan la inteligencia cultural, representando la capacidad para generar conductas apropiadas a un nuevo entorno cultural, a través de la auto-regulación y flexibilidad conductual ${ }^{180}$. La efectividad de estas habilidades y competencias en las relaciones socio-culturales depende de la que doctrina especializada denomina Metacognición que no es otra cosa que el grado de conciencia sobre nuestras actividades mentales, de nuestro propio pensamiento y aprendizaje $\mathrm{e}^{181}$.

La conciencia desempeña una función de enlace básica entre los conocimientos y habilidades culturales que determinan el grado de inteligencia cultural de cada persona y constituye junto al conocimiento cultural, el centro de gravedad que hace posible que el individuo pueda adaptarse a los culturales que le rodean ${ }^{182}$. Permite reconocer y enjuiciar las identidades colectivas ajenas, contrastarlas con las creencias o valores que conforman la identidad personal del sujeto, delimitar objetivos concretos y planificar en base a las mismas estrategias mentales que sirven de base para la interculturalidad como paradigma de gestión de la diversidad. Siguiendo la propuesta de Gros y Conteras estos objetivos son:

\footnotetext{
173 Abdallah-Pretceille, 2001, 47 ss.

174 Ang, 2007, 337.

175 Kim, 1992, 373.

176 Gardner, 2006, 123 ss.

177 Ang, 2007, 337.

338 ss.

178 Depaula - Azzollini, 2013, 37 ss.

179 Nos referimos al término competencia como «la capacidad de responder a demandas complejas y llevar a cabo tareas diversas de forma adecuada. Lo anterior supone la integración de las habilidades, prácticas, conocimientos, motivaciones, valores éticos, actitudes, emociones y otros componentes sociales y de comportamiento que se movilizan conjuntamente para lograr una acción eficaz». Cfr. Gros - Contreras, 2006, 104-105.

180 Thomas, 2008, 123 ss.

181 Antonijevic, N. y Chadwick, C. «Estrategias cognitivas y Metacognición». Revista de Tecnología Educativa, núm. 7 (4), 1982, pp. 307 ss.

182 Thomas, 2008, 123 ss.
} 
- Conocimiento y comprensión de la realidad social del mundo en que se vive y ejerce la ciudadanía democrática, a través de la incorporación de formas de comportamiento individual que capaciten a las personas para convivir en una sociedad cada vez más plural, relacionándose con los demás, cooperando, comprometiéndose y afrontando conflictos;

- Habilidades para la plena participación del ciudadano contemporáneo en aspectos fundamentales de la vida cívica, como la participación política, social y económica;

- Valoración de pluralidad, diversidad y participación del «otro» como elementos claves para la convivencia democrática en la vida moderna ${ }^{183}$.

Así pues, el objeto primordial que debe perseguir los procesos cognitivos y mentales necesarios para el desarrollo de la inteligencia cultural consisten esencialmente en entender y comprender las culturas ajenas del entorno como una propiedad esencial de la personalidad de los otros, para poder interactuar con ellos desde una posición igualitaria, nunca dominante ${ }^{184}$. Sólo así la conciencia podrá articular procesos cognitivos y estados emocionales y afectivos orientados a que los encuentros y formas de socialización expresen conductas adaptativas culturalmente inteligentes. El control de los procesos cognitivos implica la recuperación de conocimiento relevante relacionado con las interacciones culturales sobre las cuales se focaliza la atención, inhibiendo la tendencia a actuar automáticamente a través de la evaluación consciente de posibles respuestas con referencia a motivos y objetivos ${ }^{185}$. La conciencia constituye, en suma, el vehículo que permite desarrollar e incorporar la inteligencia intercultural al raciocino humano y el paradigma, por tanto, del dialogo intercultural como fuente de enriquecimiento personal, mutuo y recíproco ${ }^{186}$, en todos los tipos y entornos de socialización, ya sean físicos o digitales ${ }^{187}$.

\subsection{Conciencia y sabiduría digital}

Las formas de socialización que tienen lugar en el Ciberespacio constituyen uno de los paradigmas contemporáneos de la interculturalidad en general y de la Cibercultura en particular. Los encuentros y las comunicaciones entre personas de culturas diferentes que tiene lugar a diario en este contexto social no sólo depende de la inteligencia cultural de cada persona, sino también de sus competencias y destrezas en materia de inteligencia digital que constituye una de las inteligencias múltiples que puede incorporarse al raciocinio humano como una capacidad del pensamiento o de la propia conciencia ${ }^{188}$, mediante el aprendizaje y desarrollo de las destrezas y competencias necesarias en el uso y el manejo de las tecnologías de la sociedad de la información y del conocimiento. En concreto, este tipo de inteligencia depende de la sabiduría digital de cada sujeto, que siguiendo la propuesta de Prensky ${ }^{189}$ puede

3 Cfr. 2006, 105.

184 Abdallah-Pretceille, 2001, 42 ss.

185 Depaula - Saucedo, 2010, 11 ss.

186 Llamazares Fernández, 2016, 318 s.

187 Peterson, 2004, 41 ss.

188 Battro - Denham, 2007, 6 ss.

189 Prensky formula este concepto del término sabiduría en base a dos fuentes de conocimiento diferentes: 1) El «Oxford English Dictionary» que la define como la capacidad para encontrar soluciones prácticas, creativas y de contenido apropiado y la satisfacción emocional que implica dar soluciones a estos problemas; 2) La noción 
ser definida como «la capacidad para encontrar soluciones prácticas, creativas y de contenido apropiado, y la satisfacción emocional que implica dar soluciones a los problemas humanos $\rangle^{190}$, a través de las tecnologías 2.0 que sirven de soporte técnico al Ciberespacio. Bajo este punto de vista, la inteligencia digital es, pues, un atributo del pensamiento y, por tanto, de la conciencia humana, cuyo desarrollo capacita a los individuos para que tengan acceso a la información globalizada que circula en la Red, y a los sistemas de participación y de comunicación que representan los entornos virtuales 2.0 como elementos esenciales para el ejercicio de competencias ciudadanas en las sociedades contemporáneas ${ }^{191}$.

La adquisición de las competencias necesarias para el desarrollo de este tipo de inteligencia en base a procesos de aprendizaje metacognitivos, varía en función de que se trate de un nativo o un inmigrante digital ${ }^{192}$. Los inmigrantes digitales son aquellas personas que han nacido en las últimas décadas del siglo XX junto antes de que se produjera la Revolución Tecnológica que marca el inicio la Era Digital; mientras que los nativos digitales son quienes han nacido en los albores del siglo XXI en aquellas zonas geográficas donde se ha generalizado el uso de las tecnologías de la sociedad de la información y del conocimiento ${ }^{193}$. De acuerdo con las tesis de Prensky, el hecho de haber crecido en esta Era ha hecho posible que desde el dato bilógico de su nacimiento, los nativos digitales se encuentren familiarizados y, lo que es más importante, hayan desarrollado parte de sus capacidades cognitivas junto a los diferentes tipos de soportes tecnológicos del Ciberespacio, que les ha permitido adquirir habilidades y destrezas en relación con el uso y manejo de los mismos de forma natural y profundos cambios en la forma de pensar, de procesar la información y de relacionarse con los demás frente a las prácticas más tradicionales propias de quienes no lo son. En este sentido, están acostumbrados a recibir información de manera casi instantánea, procesarla en paralelo y desarrollar las destrezas necesarias para desarrollar tareas y actividades y socializarse cuando están conectados en el Internet de las cosas ${ }^{194}$. Los inmigrantes digitales no han tenido ocasión de adquirir las competencias propias de esta inteligencia, en base a modelos naturales emocionales e intelectuales de formación de la conciencia que tienen lugar a lo largo del devenir vital desde la más temprana niñez ${ }^{195}$. Más bien todo lo contrario. Todos ellos han desarrollado esta inteligencia mediante procesos metacognitivos que obedecen a patrones y métodos de aprendizaje que no involucran de forma connatural el uso de estas tecnologías, lo que les limita y, en muchos casos, dificulta la manera de procesar la información y su forma de pensar e interactuar en el Ciberespacio ${ }^{196}$ y en el desenvolvimiento de nuevas formas de socialización en los entornos virtuales ${ }^{197}$.

que propone Gadner como la aptitud que tiene una persona para valerse con éxito del conocimiento y del entendimiento para resolver problemas o para tomar decisiones. Vid. 2010, $95 \mathrm{~s}$.

190 Prensky, 2010,96.

191 Gros - Contreras, 2006, 107 ss.

192 Vélez Melo, 2012, 138.

193 Mollá, 2012, 10 ss.

194 Prensky, 2001, 1 ss.

195 «En este sentido, la incorporación de las TIC ha acrecentado las diferencias ya existentes entre países y grupos sociales. Actualmente se habla de la división o brecha digital. Esta expresión muestra cómo se va estableciendo una separación entre países y personas que carecen de los conocimientos y de las tecnologías que requeridas para el desarrollo de una sociedad de la información». Cfr. Gros - Contreras, 2006, 106.

196 Prensky, 2010, 2 ss.

197 Vélez Melo, 2012, 139. 
Siguiendo el paradigma de los flujos migratorios que tienen lugar en los espacios geográficos físicos, al igual que el extranjero cuando se ve obligado a socializarse en una tierra extraña con quienes pueden observarle con ojos de desconfianza por tener una identidad cultural diferenciada, los inmigrantes digitales pueden ser estigmatizados de la misma manera por los nativos, ante sus dificultades para integrarse e interactuar en la comunidad a través del Ciberespacio; y los inmigrantes, a su vez, pueden observar y estigmatizar a los nativos por su rechazo a otras prácticas y/o hábitos de socialización más tradicionales ${ }^{198}$. Para poder paliar los efectos y consecuencias derivadas de las brechas que ha abierto el desarrollo de estas tecnologías y su impacto en el acceso y creación de la Cibercultura como nuevo paradigma de la interculturalidad, Levy advierte que es necesario procesos de alfabetización digital de estos nuevos inmigrantes ${ }^{199}$ de modo que adquieran:

- Las competencias necesarias para realizar juicios de valor informados acerca de la información que pueda ser obtenida on line de modo que puedan valorarla en base a juicios morales de pensamiento crítico;

- Destrezas de lectura y comprensión en un entorno de textos dinámicos y no secuenciales;

- Destrezas para formar un pensamiento crítico mediante la construcción de bloques de información fiables procedentes de diversas fuentes, y la capacidad de recoger y evaluar tanto las noticias como las opiniones que hagan de ellas los demás en base a juicios de conciencia propios y sin sesgo;

- Habilidades de búsqueda, esencialmente basadas en motores de búsqueda en Internet;

- Destrezas para valorar las herramientas del sistema como apoyo a los formatos tradicionales del contenido;

- Concienciación acerca de la existencia de otras personas con quienes se puede entablar las formas de socialización a través de comunidades virtuales 2.0

- Competencias para comprender los riesgos inherentes a las fuentes de información ya las formas de socialización que pueden tener lugar en el Ciberespacio y para adoptar las decisiones y seguir los pasos necesarios para resolverlos ${ }^{200}$.

- Y competencias para asumir en base a la propia conciencia la densidad relacional y cognitiva de las comunidades virtuales y de la inteligencia colectiva que en ellas se producen ${ }^{201}$.

Aunque aún subsiste una brecha insalvable en la manera de procesar la información y su forma de pensar e interactuar en el Ciberespacio ${ }^{202}$; la adquisición de todas estas competencias por parte de los inmigrantes digitales en base a procesos

198 Winocur, 2009, 125.

199 Levy, 2007, 210 ss.

200 Gros - Contreras, 2006, 109.

$2012007,212$.

202 Como pone en evidencia el citado autor francés, «cada universal produce su exclusión. El universal, incluso si totaliza en sus formas clásicas, jamás lo engloba todo. Una religión universal tiene sus no creyentes y sus herejes. La ciencia tiene la tendencia a descalificar las otras formas del saber o lo que llama irracional. Los derechos del hombre tienen sus infracciones y las zonas de ausencia del derecho. Las formas antiguas de lo universal excluyen al separar a los que participan de la verdad, en el sentido o en una forma cualquiera del Imperio, de los que se encuentran relegados a la oscuridad... Lo universal sin totalidad no escapa a la regla de exclusión. Sólo que no se trata de adhesión al sentido, sino de conexión. El excluido está desconectado». Cfr. Levy, 2007, 212. 
metacognitivos, va a reducir las distancias que les separan con respecto a los nativos digitales en relación con el uso y el manejo de las tecnologías de la sociedad y del conocimiento $^{203}$. Todos ellos tendrán igualdad de oportunidades para ser alfabetizados, podrán poder participar activamente en la vida política, social, económica y cultural de la comunidad a través de Internet. en tanto en cuanto Homo Sapiens Digítales, tal y como los denomina Prensky. Individuos que aceptan la sabiduría digital en los términos antes descritos como una parte integrante de la propia conciencia, tanto en la forma en que acceden y mejoran las herramientas tecnológicas a fin de complementar sus capacidades innatas, como en la forma en que utilizan dichas herramientas para mejorar la toma de decisiones y las relaciones sociales que pueden entablar a través de la Red ${ }^{204}$. Así entendida, la inteligencia digital se integrará en el sustrato más esencial de la personalidad de los sabios digitales como el atributo propio de la conciencia personal que, junto a la inteligencia cultural, preside el dialogo y las formas de socialización interculturales que están teniendo lugar actualmente en el Ciberespacio.

\section{A modo de conclusión}

Los procesos de secularización y los flujos migratorios que han acontecido en las últimas décadas en los países occidentes han dado lugar a modelos de sociedad pleurales desde el punto de vista cultural. La existencia de esta diversidad ha sido atendida por los poderes públicos mediante políticas de gestión bien diferenciadas entre sí, que van desde la asimilación de las identidades culturales diversas a la de la mayoría de la población o su integración en claves de respeto a los diverso, pero sin que tenga lugar el mestizaje entre todos ellos en base a concepciones liberales y/o sociales del multiculturalismo. El devenir de los años ha puesto en evidencia el fracaso de las decisiones basadas en estos modelos dado que han generado situaciones de desigualdad y exclusión social tanto de los colectivos como los sujetos individuales que poseen señas de identidad diferenciadas a las de la mayoría de la población de acogida. La superación de las deficiencias de este tipo de políticas requiere la adopción de medidas en base al paradigma de la interculturalidad que es un modelo basado en políticas que fomenten el encuentro entre personas y grupos de culturas diversas y que promuevan la participación activa de la sociedad civil en todos ellos en claves de respeto y de reconocimiento de lo diferente como un valor positivo y enriquecedor para la propia comunidad. Formas de dialogo intercultural cuyo fomento ya ha dejado de ser una utopía gracias, sobre todo, a las nuevas formas de socialización que tiene lugar en el denominado Internet de las cosas en el auge la Era Digital y de la revolución de las tecnologías de la comunicación en la práctica mayoría de las sociedades de nuestros días. El libre acceso al Ciberespacio y a los entornos virtuales 2.0 se ha convertido en el nuevo paradigma de la interculturalidad. al constituir un nuevo entorno de socialización libre y universal donde pueden estar en contacto entre sí identidades individuales y/o colectivas diferenciadas en tiempo real y sin barreras geográficas ni espacio-temporales.

\footnotetext{
203 Gros - Contreras, 2006, 109.

2042010 , p. 96.
} 
El éxito de las políticas de gestión que fomenten las formas de socialización ciudadana interculturales depende de la inteligencia cultural que desarrollen quienes residen en este tipo de comunidades plurales y que constituye una de las inteligencias múltiples que se incorporan al raciocinio humano mediante actos metacognitivos o de conciencia. Este atributo esencial de la personalidad es la que permite adquirir y desarrollar a lo largo del devenir vital las competencias y destrezas culturales que son del todo necesarias para que este tipo de encuentros tengan lugar en claves de respeto y tolerancia hacia lo diferente y que sean considerados como algo positivo y enriquecedor por parte de sus protagonistas. A saber: 1) El reconocimiento de la cultura propia y ajena como un valor positivo; y 2) Desarrollar estrategias y habilidades de ajuste entre las señas de identidad, a través de procesos de aprendizaje alternativos culturalmente adaptables que hagan posible el dialogo. Junto el desarrollo de este tipo de inteligencia, el éxito de las relaciones sociales interculturales que tiene lugar en el Ciberespacio depende de la sabiduría digital de cada sujeto, esto es, su capacidad intelectual para encontrar soluciones prácticas, creativas y de contenido apropiado, y la satisfacción emocional que implica dar soluciones a los problemas humanos que tiene lugar en la Web. Este tipo de inelegancia es desarrollada de forma natural mediante procesos internos de formación de la propia conciencia, por quienes han nacido en los albores del siglo XXI familiarizados con el uso y el manejo de las tecnologías de la sociedad de la información y del conocimiento y los avances técnicos que se producen en este campo día a día. En cambio, el resto de ciudadanos que se relacionan con los demás en Internet han sido alfabetizados para poner coto a las berraras tecnológicas que les separan de los nativos digitales. Sólo así la inteligencia digital se integrará en el sustrato más esencial de la personalidad de los sabios digitales como el atributo propio de la conciencia personal que, junto a la inteligencia cultural, preside el dialogo y las formas de socialización interculturales que están teniendo lugar actualmente en el Ciberespacio. La conciencia es, en conclusión, el atributo de la personalidad paradigma de la interculturalidad y la principal fuente de producción de la Cibercultura.

\section{Bibliografía}

M. Abdallah-Pretceille, Lo intercultural como paradigma para pensar la diversidad, http://www2. uned.es/congreso-inter-educacion-intercultural/pretceille_espanol.pdf [acceso: 20-01-2017].

M. Abdallah-Pretceille «Interculturalism for thinking about diversity», Intercultural Education, 17 (2005) 475-483.

M. Abdallah-Pretceille, La educación intercultural, Madrid, 2001.

S. Acedo Osuna, «Interactuantes e interactuados a través de la Web 2.0», R. Aparici, (Coord.) Conectados en el Ciberespacio, Madrid, 2010, 135-149.

R. Alexy, Teoría de los Derechos Fundamentales, Madrid, 1997.

S. Ang y otros, «Cultural intelligence: Its measurements and effects on cultural judgments and decision making, cultural adaptation and task performance», Management and Organization Review, 3 (2007) 335-371.

N. Antonijevic - C. Chadwick, «Estrategias cognitivas y Metacognición», Revista de Tecnología Educativa, 7 (1982) 307-321.

R. Aparici, «Conectividad en el ciberespacio», R. Aparici, (Coord.) Conectados en el Ciberespacio, Madrid, 2010, 9-23. 
J.P. Barlow, «Crime and Puzzlement», 1990. https://w2.eff.org/Misc/Publications/John Perry_Barlow/HTML/crime_and_puzzlement_1.html [acceso: 20-01-2017].

J.P. Barlow, Declaraciön de Indpendencia del Ciberspacio, 1996. http://www.uhu.es/ramon. correa/nn_tt_edusocial/documentos/docs/declaracion_independencia.pdf [acceso: 20-012017].

H.G. Barnett y otros, «Acculturation: An Exploratory Formulation», American Antrophologist, 56 (1954) 973-1000.

A.M. Battro - P.J. Denham, Hacia una inteligencia digital, Buenos Aires, 2007.

D. Beer, «Social network(ing) sites... revisiting the story so far: A response to Danah Boyd \& Nidole Elison», Journal of Computer-Mediated Communication, 13 (2008) 516-529.

M.T. Bendito Cañizares, La autorregulación: una alternativa para la protección de los «menores digitales», Madrid, 2012.

K. Bermúdez, Anderson y otros. Mediación intercultural. Una propuesta para la formación, Madrid, 2008.

A. Calvo Espiga, «Tolerancia, multiculturalismo y democracia: límites de un problema», Laicidad y libertades. Escritos jurídicos, 3 (2003) 73-106.

(I) M. Castells, «Internet, libertad y sociedad: una perspectiva analítica», POLIS 4 (2003) $1-25$.

(II) M. Castells, «La dimensión cultural de Internet», Andalucía Educativa, 36 (2003) 7-10.

J.M. Contreras Mazarío, «Inmigración e interculturalidad religiosa», A. Marcos del Cano, (Coord.) Inmigración, multiculturalismo y Derechos Humanos, Valencia, 2009, 175234.

L. Cotino Hueso, «Un intento de respuesta a muchas de las dudas que presenta cada día internet respecto de las libertades de expresión y de información», L. Cotino Hueso, (Dir.) Libertad en internet, Valencia, 2006, 19-40.

R. De Asis Roig, «Derechos Humanos. Integración y diferenciación», A. Marcos del Cano, (Coord.) Inmigración, multiculturalismo y Derechos Humanos, Valencia, 2009, 29-50.

M. Delgado Ruiz, Ciudad líquida, ciudad interrumpida: la urbs contra la polis, Antioquia, 1999.

P. Depaula - B. Saucedo, «Globalización, Cultura y desarrollo de Inteligencia Cultural en contextos militares. Algunas aproximaciones teóricas», ReDiUCMN, 22 (2010) 1-15.

P. Depaula - S. Azzollini, «Análisis del modelo Big Five de la personalidad como predictor de la inteligencia cultural», PSiENCIA. Revista Latinoamericana de Ciencia Psicológica, 5 (2013) 35-43.

A. Fascioli, «El concepto de sociedad civil en J. Habermas», Revista ACTIO, 11 (2009) 33-47.

A. Ferguson, Ensayo sobre la historia de la sociedad civil. Introducción, traducción y notas de M. Isabel Wences Simon, Madrid, 2010.

A. Fernández-Coronado - G. Suárez Pertierra, Identidad social, pluralismo religioso y laicidad del Estado, Madrid, 2013.

A. Fernández-Coronado - S. Pérez Álvarez, «La libre formación de la conciencia del menor a través de Internet», S. Pérez Álvarez y otros, (Dirs.) Menores e Internet, Pamplona, 2013, 185-212.

W.A. Galtson, «The impact of the Internet on Civil life: an early assessment», V. Gehring, (Ed.) The Internet in Public Life, Oxford, 2004, 59-77.

H. Gardner, Multiple intelligences. New Horizons, Nueva York, 2006.

C. Giménez, «Pluralismo, multiculturalismo e interculturalidad. Propuesta de clarificación y 
apuntes educativos», Educación y Futuro: Revista de investigación aplicada y experiencias educativas, 8 (2003) 1-24.

B. Gros - D. Contreras, «La alfabetización digital y el desarrollo de competencias ciudadanas», Revista Iberoamericana de Educación, 42 (2006) 103-126.

J. Habermas, Teoría de la acción comunicativa, Madrid, 1999.

D. Held, «Cultura nacional, globalización de las comunicaciones y comunidad política», V. Sampedro - M. Llera, (Ed.) Interculturalidad: interpretar, gestionar y comunicar, Barcelona, 2003, 33-50.

H. Heller, Teoría del Estado. Traducción Luis Tubio, México, 1942.

S.P. Huntington, El choque de civilizaciones y la reconfiguración del orden mundial (trad. esp.), Buenos Aires, 2001.

Informe de la UNESCO Alfabetización funcional: cómo y porqué, Paris, 1970.

Y.Y. Kim, «Intercultural communication competence: A systemsthinking view», W.B. Gudykunst - Y.Y. Kim, (Eds.) Readings on communicating with strangers: An approach to intercultural communication, Nueva York, 1992, 371-381.

R. Kosinets, Netnography: Doing Ethnographic Research Online, Londrés, 2010.

W. Kymlicka, Ciudadanía multicultural. Una teoría liberal de los derechos de las minorías, Barcelona, 1996.

W. Kymlicka, Filosofía política contemporánea: una introducción (trad. esp.), Barcelona, 1995.

M. Lema Tomé, Laicidad e integración de los inmigrantes, Madrid, 2007.

A. Leturia Navaroa, «Laicidad y diálogo interreligioso en sociedades plurales», A. Fernández-Coronado y otros, (Coords.) Libertad de conciencia, laicidad y Derecho, 2014, Pamplona, 547-571.

P. Levine, «The Internet an Civil Society», V. Gehring, (Ed.) The Internet in Public Life, Oxford, 2004, 79-99.

P. Levy, Cibercultura. La cultura de la sociedad digital (trad. esp.), 2007, México.

P. Levy, Ciberdemocracia. Ensayo sobre filosofía politica (trad. esp.), Barcelona, 2004. Libro Blanco del Consejo de Europa sobre Dialogo Intercultural, Estrasburgo, 2008.

D. Llamazares Fernández, «Educación en valores y enseñanza religiosa en el sistema educativo español», G. Suárez Pertierra - J.M. Contreras Mazarío, (Dirs.) Interculturalidad y educación en Europa, Valencia, 2005, 395-422.

(I) D. Llamazares Fernández, Derecho de la libertad de conciencia I: Conciencia, tolerancia y laicidad, Madrid, 2011.

(II) D. Llamazares Fernández, Derecho de la libertad de conciencia II: Conciencia, identidad personal y solidaridad, Madrid, 2011.

D. Llamazares Fernández, «Tolerancia, laicidad y dialogo intercultural», A. Castro Jover, (Dir.) Interculturalidad y Derecho, Pamplona, 2013 59-80.

D. Llamazares Fernández, «Tolerancia y solidaridad», Laicidad y libertades. Escritos jurídi$\cos , 16$ (2016) 287-320.

L. Lugo. «Educación virtual y hegemonía cultural: una mirada desde la interculturalidad», Razón y Palabra, 621 (2016).

G. Malgesino - C. Giménez Romero, Guía de conceptos sobre migraciones, racismo e interculturalidad, Madrid, 1997.

A.M. Marcos del Cano, «El proceso de integración de la inmigración. Luces y sombras», A.M. Marcos del Cano, (Coord.) Inmigración, multiculturalismo y Derechos Humanos, Valencia, 2009, 121-147.

K. Marx, Contribución a la crítica de la Teoría económica (trad. esp.), México, 1989. 
O. Meunier, «Les approches interculturelles dans le système scolaire français: vers une ouverture de la forme scolaire à la pluralité culturelle?», Revue de l'Association Française de Sociologie, 3 (2008) 1-15.

I. Mollá y otros, Informe Técnico: Acercamiento a la Comprensión de la Sabiduría Digital, Lima, 2012.

P. Nuevo López, La Constitución educativa del pluralismo. Una aproximación desde la teoría de los derechos fundamentales, La Coruña, 2009.

L. Olivé, Multiculturalismo y pluralismo, México, 1999.

Y. Onghena, «Reinterpretar para gestionar la diversidad cultural», V. Sampedro - M. Llera, (Ed.) Interculturalidad: interpretar, gestionar y comunicar, Barcelona, 2003, 51-68.

J. Ortega y Gasset, Ideas y creencias, Madrid, 1995.

B. Parekb, Repensando el multiculturalismo (trad. esp.), Madrid, 2000.

A.E. Pérez Luño, Los Derechos Humanos en la Sociedad Tecnológica, Madrid, 2012.

B. Peterson, Cultural intelligence: A guide to working with people from other cultures, 2004, Boston.

M. Prensky, «Digital Natives, Digital Inmigrants», On the Horizon, 9 (2001) 1-6.

M. Prensky, «Homo Sapiens Digital: De los inmigrantes y nativos digitales a la sabiduría digital», R. Aparici (Coord.) Conectados en el Ciberespacio, Madrid, 2010, 93-106.

A.M. Raad, «Exclusión Digital: Nuevas Caras de Viejos Malestares», RevistaMad 14 (2006) $0-6$.

J.A. Rodríguez García, La inmigración islámica en España. Su problemática jurídica, Madrid, 2007.

C. Ruiz Miguel, «El constitucionalismo cultural», Cuestiones Constitucionales, 9 (2003) 201-216.

R. Ruiz Ruiz, «Liberalismo y comunitarismo: Dos perspectivas antagónicas del fenómeno multicultural», F.J. Ansuategui Roig y otros, (Eds.) Derechos fundamentales, valores y multiculturalismo, Madrid, 2005, 35-64.

G. Sartori, Pluralismo, multiculturslismo e estranei, Roma, 2000.

S. Schwartz, "Are there universal aspects in the structure and content of human values?», Journal of Social Issues, 50 (1994) 19-45.

R. Serra Cristobal, «La discriminación múltiple. ¿Un nuevo enfoque sobre la igualdad?», V. Gimeno Sendra - M.T. Regueiro García, (Coords.) Nuevas tendencias en la interpretación de los Derechos Fundamentales, Madrid, 2015, 133-146.

S. Tarodo Soria, Libertad de conciencia y derechos del usuario de los servicios sanitarios, San Sebastián, 2004.

M. Tascón - Y. Quintana, Ciberactivismo. Las nuevas revoluciones de las multitudes conectadas, Madrid, 2013.

C. Taylor, El multiculturalismo y «la política del reconocimiento» (trad. espa.), México, 2009.

D.C. Thomas y otros, «Cultural Intelligence: Domain and Assessment. Internacional», Journal of Cross Cultural Management, 8 (2008) 123-143.

M. Torres Soriano, «Terrorismo yihadista y nuevos usos de Internet: la distribución de propaganda», Boletín Elcano, 116 (2009) 1-9.

RC. Types - RE. Christal Recurrent Personality Factors Based on Trait Ratings, 1961. http:// www.dtic.mil/dtic/tr/fulltext/u2/267778.pdf [acceso: 20-01-2017].

S. Ugarte Fernández, «La Web 2.0: Una verdad incómoda», R. Aparici, (Coord.) Conectados en el Ciberespacio, Madrid, 2010, 189-196.

J. Vallespir, «Interculturalismo e identidad cultural», Revista Interuniversitaria de Formación del Profesorado, 39 (1999) 45-56. 
J.A. Vélez Melo, «Sabios digitales en territorios virtuales», Miradas, 10 (2012) 135-143.

S. Watchbroit, «Reiance and reliability: The problem of information on the Internet», V. Gehring, (Ed.) The Internet in Public Life, Oxford, 2004, 29-42.

R. Winocur, Robinson Crusoe ya tiene celular. México, 2009.

J.M. Young, «Vida política y diferencia de grupo: Una crítica del ideal de ciudadanía universal», C. Castells, (Coord.) Perspectivas feministas en teoría política, Barcelona, 1996, 99-126. 